\title{
Estimating regional variations in adult mortality in Zambia
}

\author{
Vesper H. Chisumpa ${ }^{1,2}$ \& Nicole De Wet ${ }^{1}$ \\ ${ }^{1}$ Demography and Population Studies Programme, School of Social Sciences, University of the \\ Witwatersrand, Johannesburg, South Africa \\ ${ }^{2}$ Department of Population Studies, School of Humanities and Social Sciences, University of Zambia, \\ Lusaka, Zambia \\ vchisumpa@yahoo.com \\ Nicole.dewet@wits.ac.za
}

\begin{abstract}
Background: A dearth of regional level adult mortality estimates exists in Zambia. Regional adult mortality rates reflect inequalities in socioeconomic conditions and health service provision. Adult mortality rates are useful indicators for monitoring effectiveness and impact of health interventions (HIV/AIDS antiretroviral therapy (ART), tuberculosis (TB) and malaria) at regional level. Previous studies have not produced adult mortality rates at regional level.

Data Source and Methods: Using data from the 2010 census, this study estimated adult mortality rates at regional level for age group 15-59 years. Age-specific mortality rates (ASMRs), cause-specific mortality rates (CSMRs), standardised mortality rates (SMRS) and probabilities of dying between age I5 and 60 years $\left({ }_{45} q_{15}\right)$ were computed. Correlations with HIV prevalence and literacy rates, and mortality rates were also computed.

Findings: Adult mortality rates varied across all provinces. The ${ }_{45} q_{15}$ was highest for males in Western province, $59 \%$ and lowest in North-western province, $36.7 \%$. For females, ${ }_{45} q_{15}$ was highest in Copperbelt province, $47.9 \%$ and lowest in North-western province, $34.8 \%$.

Conclusion: HIV prevalence and literacy rates were positively correlated with regional adult mortality rates. Health policies and programmes aimed at reducing adult mortality should, therefore, be tailored to recognise the regional variations in mortality rates.
\end{abstract}

Keywords: regional-variations, adult mortality, estimation, Zambia, standardised mortality rates

\section{Introduction}

Adult mortality, measured by the probability of dying between the age of 15 and 60 years $\left({ }_{45} q_{15}\right)$, still remains a major health challenge in most developing countries. Adult mortality is closely linked to the attainment of major development goals such as Sustainable Development Goals (SDGs). A significant impact on morbidity and mortality of adults in the age group 15-59, therefore, affects the attainment of these goals as well as the socioeconomic development of a country. Studies have documented the impact of adult mortality at household, community and national level (Ainsworth, Beegle and Koda 2005; Bradshaw and Timaeus 2006; Dzekedzeke, Siziya and Fylkesnes 2008; Muhwava, Herbst and Newell 2013). Adult mortality, however, remains the least studied compared to infant and child mortality, and maternal mortality in sub-Saharan Africa. Consequently, infant and child mortality estimates as well as maternal mortality estimates are population segment in age group 15-59 in the regions are the drivers of development in these areas, therefore, if their social and health needs are not widely available than those of adult mortality at national and regional level. As a result, there are more programmes and interventions targeting infant and child, and maternal mortality than adult mortality.

Regional variations in mortality of any country to a great extent reflect the inherent inequalities in livelihoods, access to social amenities, health care, and poverty in populations (Khosravi, Taylor, Naghavi et al. 2007; Saikia, Jasilionis, Ram et al. 20I I). In most cases, policies and interventions are designed in a manner that does not pay attention to the variations in mortality existing at sub-national level. Regions with higher levels of mortality should be targets of policies and programme interventions to reduce mortality rates. There is need, therefore, to understand the regional variations in adult mortality so as to be able to design interventions that specifically target the adult's health needs tailored to the regional context. Furthermore, the planned for and addressed this in turn affects the development of these regions and ultimately the country. 
In Zambia, there is a dearth of reliable adult mortality estimates at regional level for monitoring adult mortality levels as well as the implementation and impact of health programmes. For example, government of the republic of Zambia and its cooperating partners have been implementing HIV/AIDS antiretroviral therapy (ART) and tuberculosis health interventions to address HIV/AIDS related morbidity and mortality at regional level in a homogenous manner without considering the regional variations in adult mortality rates. Studies have shown that countries like Zambia receiving development assistance for health (DAH) in implementing ART programmes have reported reductions in adult mortality rates (Bendavid, Holmes, Bhattacharya et al. 2012; United Nations 20I4); however, the extent of this reduction in mortality rates is not known at sub-national level. The lack of adult mortality estimates at the regional level can be attributed a weak civil and vital registration system existing in Zambia (Mikkelsen, Phillips, AbouZahr et al. 2015). Though a health facility based district health information system (DHIS) exists in most of the districts in Zambia. The system, however, has its own weaknesses as the quality of data varies from year to year and district to district (Banda 20I5). Reliable adult mortality estimates cannot, therefore, be derived from the DHIS at regional level.

Previous studies have produced adult mortality estimates at national level; however, a gap remains at sub-national-provincial-level in Zambia (Timaeus and Jasseh 2004; Gakidou and King 2006; Obermeyer, Rajaratnam, Park et al. 2009; Chisumpa and Dorrington 201I; Reniers, Masquelier and Gerland 20II; Masquelier 2013; United Nations 2013a; Central Statistical Office (CSO) [Zambia], Ministry of Health $(\mathrm{MOH})$ [Zambia] and ICF International 20I4; World Health Organization (WHO). 2014). The few studies that have produced mortality estimates at sub-national level have done so at rural-urban residence level focusing on maternal mortality (Banda, Fylkesnes and Sandøy 2015) and others are localised focusing on small areas (Kelly, Feldman, Ndubani et al. 1998; Rathod, Timæus, Banda et al. 2016).

It is imperative, therefore, to know and understand the regional differentials in adult mortalit rates; bring to the fore which regions of Zambia experience high adult mortality rates so that more suitable specific health interventions can be designed and targeted at these particular regions to reduce adult mortality.

Using data from the 2010 population census and constructing two-parameter relational life tables allowing for the effect of the AIDS epidemic on adult mortality; the study estimated the probabilities of dying between age 15 and 60 years at regional level and examined the variations. Therefore, the contribution of the study lies in estimating adult mortality rates at regional level as well as in establishing the relationship between with HIV prevalence rate and literacy rate in line with the proximate determinants framework of adult mortality (Rogers, Hummer and Krueger 2005). The study, therefore, provides important indicators for decisionmaking in resource allocation, policy and programme interventions aimed at addressing adult mortality at sub-national level. The study sought to answer the research questions: what are the levels of adult mortality at regional level in Zambia? And how are the regional adult mortality rates related to HIV prevalence rates and literacy rates?

\section{Literature Review and Theoretical Framework}

At global level adult mortality rates declined from 198 deaths per 1,000 persons alive at age 15 and above or $I$ in 5 in the period 1990-1995 to 157 deaths per I,000 in the period 2010-2015; in Africa, however, the adult mortality rate remains the highest globally with a rate of 296 deaths per I,000. Males have the highest rate at 317 deaths per 1,000 and females at 275 deaths per I,000. A ratio of 1.2 times higher than female mortality (United Nations 2013a). Adult mortality rates in Africa increased through the 1990s and reached a peak in early 2000s mainly due to HIV/AIDS (Bendavid, Holmes, Bhattacharya et al. 2012; United Nations 2013a). Studies have also revealed that adult mortality varies by demographic, behavioural, socioeconomic, geographic and biological factors (Rogers, Hummer and Krueger 2005; Bradshaw and Timaeus 2006; Rogers, Everett, Saint Onge et al. 2010; Misganaw, Mariam and Araya 2013; Masquelier, Reniers and Pison 2014; Rossier, Soura, Duthe et al. 2014). Demographically, adult mortality varies by age, it increases progressively with age. Mortality is generally higher among males than females (Rogers, Hummer and Krueger 2005; Masquelier 20/3). Lower mortality is experienced among the married than the non-married (Waite 1995). Geographically, rural areas experience higher mortality than urban areas due to differences in health infrastructure and accessibility to health services (Weldearegawi, Spigt and Berhane 20I4). Adult mortality varies by education attainment. Higher level of education is associated with lower mortality (Hummer and Lariscy 20I I; Hummer and Hernandez 2013). Wealth status has also been associated with adult mortality; individuals with higher income experience lower mortality than those with lower income (Rogers, Hummer and Everett 20/3). Behavioural factors, such as, smoking and 
alcohol consumption have been associated with higher adult mortality (Rogers, Everett, Saint Onge et al. 2010; Misganaw, Mariam and Araya 20/3). Biological factors are closely associated with adult mortality because of health conditions, such as, HIV/AIDS and non-communicable diseases (NCDs) that have been responsible for high rates of adult mortality(Rossier, Soura, Duthe et al. 20I4; United Nations 2014; World Health Organization (WHO). 2014).

At sub-regional level adult mortality rates vary from region to region in Africa. Adult mortality rates are higher in Southern Africa and lower in Western Africa. Higher adult mortality rates in Southern Africa have been attributed to the generalised HIV/AIDS epidemic experienced by the countries in the region (Reniers, Masquelier and Gerland 20II). Previous studies show that a number of sub-Saharan African countries do not only have to deal with the AIDS epidemic but also with the epidemic of NCDs (Rossier, Soura, Duthe et al. 20I4; Murray, Ortblad, Guinovart et al. 20l4). Several studies have been conducted to estimate and compare variations in adult mortality rates across countries in Africa (Bicego 1997; Timaeus and Jasseh 2004; Reniers, Masquelier and Gerland 20II; Adebowale and Adedini 2014). Adebowale and Adedini (2014) for example, used census survival methods and INDEPTH model life tables to estimate levels of adult mortality in Kenya, Rwanda, Senegal, South Africa and Tanzania using census data. They found that the probability of dying between age 15 and 60 years varied across the five countries. South Africa had the highest probabilities of dying, 79.4 per cent for males and 81.7 per cent for females. They attributed the high adult mortality rates to the AIDS epidemic. Adebowale and Adedini (2014: 94) did not use the Brass Growth Balance method because data on household deaths were not available. In sub-Saharan Africa, few studies have produced adult mortality rates at sub-national level. This because of a paucity of good quality data at sub-national level coupled with weak civil and vital registrations systems (Dorrington, Timaeus, Moultrie et al. 2004; Hosegood and Timaeus 2004; Udjo and Lalthapersad-Pillay 20I4; Mikkelsen, Phillips, AbouZahr et al. 2015).

In Zambia, adult mortality estimates by the United Nations Population Division (UNPD) in the period 20I0-20I5 were 458 deaths per I,000 for males, 450 deaths per I,000 for females, and 454 deaths per I,000 in total (United Nations 2013a). Other studies have also produced estimates of adult mortality rates in Zambia (World Health Organization (WHO) 2009; Chisumpa and Dorrington 201 I; Masquelier 2013; Central Statistical Office (CSO) [Zambia], Ministry of Health (MOH) [Zambia] and ICF International 20I4;
World Health Organization (WHO). 20I4). However, despite the observed difference in the adult mortality estimates from these studies what is evident is that adult mortality remains high in Zambia. These studies, however, did not produce adult mortality rates at regional level. A dearth of information on adult mortality indicators exist at subnational level. The few studies available have focused on either maternal mortality or pregnancy-related deaths at sub-national level and mostly rural-urban residence or localised small areas. For example, a study by Banda (20I5) used routine data collected by the Ministry of Health through the District Health Information System (DHIS) to examine geographical variations in maternal mortality. The study found that the life-time risk of maternal death was higher in rural provinces (Muchinga, Northern and Luapula) than urban ones. Banda (20I5) attributed the variations in maternal mortality rates in the regions to differences in socioeconomic, demographic and environmental conditions obtaining in the provinces.

Another study by Banda et al. (2015) estimated rural-urban differentials in pregnancy-related mortality using 2010 census data and applied a combination of the Generalised Growth Balance method (Hill 1987) and Synthetic Extinct Generations method (Bennett and Horiuchi 198I, 1984); found high female adult mortality and pregnancy-related mortality in both rural and urban areas. The study also found higher adult female mortality in the age groups 25-29 and 30-34 in urban areas than rural areas.

A localised study by Rathod et al. (2016) used data from a multi-year (2004-20II) population-level survey of Lusaka urban district to derive adult mortality estimates of the probability of dying between age 15 and 60 years. The study found higher than expected adult mortality rates for Lusaka urban district; the probability of dying $\left({ }_{45} q_{15}\right)$ for males was 62.6 per cent while for females it was 53.7 per cent. High mortality rates were observed among young adults in age group 20-40 years. They also found that adult mortality rates were twice as high in low-cost housing communities compared to high-cost housing communities. The leading causes of death were tuberculosis, HIV/AIDS and malaria.

A gap in adult mortality estimates at regional level exists in Zambia. This study estimated adult mortality rates at national, rural-urban residence and provincial levels to try and close the gap. Correlations between HIV prevalence and literacy rates and regional adult mortality rates were also established. 
Proximate Determinants of Adult Mortality Framework

The study is anchored in the proximate determinants framework of adult mortality proposed by Rogers et al., (2005). The framework posits that demographic characteristics, distal causes, proximate factors influence adult mortality as an outcome. Distal factors, for example, social economic status (education, income), geographical factors (region of residence, rural-urban residence) indirectly influence adult mortality whereas proximate factors, that is, health behaviours, health conditions (e.g. HIV/AIDS) and physiological conditions have a direct influence on adult mortality. Demographic factors (e.g. age, sex) are related to overall and cause-specific adult mortality and act through other factors.

The study hypothesised that first, HIV prevalence rates are positively associated with regional adult mortality rates; and second, literacy rates are negatively associated with regional adult mortality rates. There is growing interest to understand behavioural, health and genetic factors associated with adult mortality among demographers. In this study, however, due to the limited information available on the deceased persons-that is, age, sex, region of residence and type of residence-not all the earlier mentioned factors are considered. An attempt is made to use proxy variables, for proximate factors HIV prevalence rate (health conditions); and for distal factors, literacy rate (social economic factors).

\section{Data and Methods}

Study setting

Zambia is a landlocked country located in the southern African region, surrounded by eight neighbouring countries: Angola, Botswana, Congo DRC, Malawi, Mozambique, Namibia, Tanzania, and Zimbabwe. Zambia has a land area of 752, 612 square kilometres. The country is divided administratively into 10 provinces (regions): Central, Copperbelt, Eastern, Luapula, Lusaka, Muchinga, Northern, North-western, Southern and Western; then into 104 districts which are divided into 150 constituencies and then I,430 wards at the lowest level (Central Statistical Office (CSO). 20I2).

In 2010, the population was 13.1 million with 49 per cent males and $5 \mathrm{I}$ per cent females. The adult mortality age group-15-59-constituted about half of the total population. About 60 per cent of the population reside in rural areas while 40 per cent live in urban areas, making Zambia one of the urbanised countries in the southern Africa sub-region (Central Statistical Office (CSO) 20I2). The population growth rate, between 2000 and 2010, was 2.8 per cent per annum. The life expectancy at birth for both sexes was 51.2 years in 2010 , for males it was 49.2 years and females 53.4 years; it was higher in rural areas (5I.7 years) than in urban areas (50.8 years) (Central Statistical Office (CSO) 20I2). The total fertility rate (TFR) was 5.9 children per woman; higher in rural areas (7.0) than in urban areas (4.6) (Central Statistical Office (CSO) 20I2). Recent estimates from the 2013/14 Zambia Demographic and Heath Survey indicate a TFR of 5.3 at national level; 3.7 in urban areas and 6.6 in rural areas (Central Statistical Office (CSO) [Zambia], Ministry of Health (MOH) [Zambia] and ICF International 20I4).

Zambia is one of the countries in the southern African region that has experienced a generalized epidemic of HIV/AIDS with an HIV prevalence rate of I 3.3 per cent in the age group 15-49 years; with HIV prevalence rates of 18.2 per cent and 9.1 per cent in urban and rural areas, respectively. HIV prevalence rates are higher among females (I5.I per cent) than males (II.3 per cent) (Central Statistical Office (CSO) [Zambia], Ministry of Health (MOH) [Zambia] and ICF International 20I4). Approximately 6I per cent of the Zambian population live below the poverty line of I dollar a day. Poverty is more endemic in rural areas (77.9 per cent) than in urban areas (27.5 per cent) (Central Statistical Office (CSO) 20I2).

Previous population censuses conducted in 1980 , 1990 and 2000 did not collect detailed household information on deaths to facilitate estimation of regional variations in adult mortality. For instance, the 1990 census did not collect information on the ages of the deceased persons but only sex; whereas the 2000 census did not ask any questions on household deaths. Apparently, there are no documented reasons for this action. The 2010 population census, however, collected adequate information on household deaths useful for estimating adult mortality rates and examining the variations at regional level.

\section{Data}

Cross-sectional data from the 10 per cent sample of the 2010 Zambia census of population and housing were utilised to estimate adult mortality rates by region and examine variations in Zambia. A single questionnaire was used to capture individual, household and housing characteristics from the population. The 2010 census collected information on household deaths in the last 12 months (October 2009 to October 2010). A question, "Is there any member of this household who died since October 2009?" was asked. If yes, additional questions were asked: "What was the sex of the deceased?"; "What was the age of the deceased?" and "What was the cause of death?" The response categories for the causes of death were pre-coded in the questionnaire. These questions enabled information on the sex, age 
and cause of death of the deceased person to be collected (Central Statistical Office (CSO). 20I2). It should be noted, however, that there is a limitation in the way information on causes of death was collected as the standard medical procedure to establish cause of death was not followed. The respondents in the households provided the information on causes of death which in itself has its own biases with respect to the accuracy of the responses.

Population age data obtained from censuses suffer from problems of age heaping, age exaggeration, age digit preference ( 0 and 5 ) among others. Also, data on household deaths are faced with issues of quality such as under-reporting of deaths, reference-period errors, age misreporting, and death taboo (unpleasantness of the event in an African context). Studies have noted that information on deaths and causes of death is not easy to collect because of the nature of the event of death; it carries with a lot of emotions. In some African cultures, it is almost taboo to talk about death. Furthermore, deaths in dissolved households are rarely captured (Brass, Coale, Demeny et al. 1968; Brass 1975; Hill and Trussell 1977; Hill 2003; Timaeus and Jasseh 2004; Chisumpa and Dorrington 20I I; Moultrie, Dorrington, Hill et al. 20।3; Udjo 20|4).

Consequently, to minimise some of the age misreporting errors in the population age data the study developed its own spreadsheet to apply the Arriaga (1994) light smoothing method. The method assumes that a second degree polynomial passes by the mid-point of each three consecutive 10-year age groups and then integrates the 5-year age group (Arriaga, Johnson and Jamison 1994). The method does not modify the total population figures. The Arriaga light smooth method combines the initial 5year age group population distributions into 10 -year age groups and then split them back again into 5-year age groups thereby redistributing the populations in each age group to correct for the age misreporting in the data. The light smoothing method was used as opposed to the strong smoothing because the age misreporting was not severe; there were slight irregularities in other ages. The smoothing of the population age data was done in preparation for the application of the Brass Growth Balance (BGB) method (Brass 1975). For data on household deaths, they were evaluated for completeness in reporting of deaths using the BGB method at regional (province), rural-urban residence and national levels separately. The Brass Growth Balance method estimates the completeness of reporting of deaths relative to an estimate of the population. The method is based on the assumption that in a stable and closed population where data on age and deaths are correctly reported, the growth rate is equal to the birth rate less the death rate: $N(x)=r(x+) \cdot N(x+)+D(x+)$, where $N(x)$ is the number of persons at age $x ; r(x)$ is the rate of growth of the population aged $x+; N(x+)$ is the population aged $x+$; and $D(x+)$ are deaths in the population aged $x+$. The final expression for adjusting completeness of reporting of deaths is: $\frac{N(x)}{N(x+)}=r+\frac{1}{c} \cdot \frac{D^{\prime}(x+)}{N(x+)}$, where $1 / c$ is the reciprocal of completeness of death reporting. A detailed elaboration of the method can be found elsewhere (Brass 1975; United Nations 2002; Moultrie, Dorrington, Hill et al. 2013).

The study utilised a Brass Growth Balance method spreadsheet developed by Moultrie et al., (2013) and made available by the International Union for the Scientific Study of Population (IUSSP) on its website (www.iussp.org). The 2000 census population agesex data and 2013/2014 demographic and health survey sibling survival data were also utilised in producing alternative adult mortality rates for validating the $B G B$ mortality rates.

\section{Analysis}

The study used Stata version 12.1 and Microsoft Excel 2007 as software packages for estimation. Descriptive statistics in form of percentages were computed first to describe the distribution of adult deaths by age, sex, cause of death, residence, and province. Second, crude death rates for the adult mortality age group 15-59 were computed for each province. In order to account for the effect of age on adult mortality, since age is closely associated with HIV/AIDS mortality; indirect standardization was performed by applying national age-specific mortality rates in the age group 15-59 years as a set of standard rates used to compute expected deaths for each province. Standardized mortality rates (SMRs) were computed with 95 per cent confidence intervals (Cls) for each province and used for comparison (Bruce, Pope and Stanistreet 2008). The Standardized mortality rates (SMRs) were computed as:

$$
\mathrm{SMR}=\frac{\text { Total number of observed deaths (in province) }}{\text { Total number of expected deaths (in province) }}
$$

and the 95 per cent confidence intervals were computed as:

$$
S M R=S M R \pm 1.96 \times \frac{S M R}{\sqrt{\text { Observeddeaths }}}
$$

Adult mortality rates, ${ }_{45} q_{15}$, for each province, ruralurban residence, and by sex were computed from life tables constructed after assessment and adjustment of the reported household deaths for completeness by applying the Brass Growth Balance method as 
elaborated by Dorrington (2013: 196-204). The BGB method was selected because as mentioned earlier only the 2010 population census collected useful information on household deaths, previous censuses did not.

As mentioned earlier, the BGB method spreadsheet developed by Moultrie et al., (2013) was utilized for computations of adult mortality rates at all levels. The spreadsheet has in-built relational model life tables based on the Brass logit transformation which allow for production of smooth or adjusted mortality rates that are used in constructing a life table from which adult mortality rates are estimated (Dorrington 2013: 198). The probabilities of dying between age 15 and 60 years were estimated as

from a fitted life table:

$$
{ }_{45} q_{15}=1-\left(\frac{l_{60}^{\text {fitted }}}{l_{15}^{\text {fitted }}}\right) \text { as }
$$

elaborated by Dorrington (2013: 196-204).

The study chose the AIDS model life table in the BGB spreadsheet as a standard in deriving the adult mortality estimates at all levels, since Zambia experiences high HIV prevalence rates as noted earlier. In applying the BGB method it was assumed that migration did not play a significant role in determining population dynamics at national level as an estimate of net migration rate of -0.6 migrants per 1,000 population in the period $2010-2015$ is negligible (United Nations 20/3b). At sub-national level, however, net migration was estimated at regional level using information on province of enumeration and province of previous residence. The methodology utilized for estimating regional migration is elaborated elsewhere (Moultrie, Dorrington, Hill et al. 2013).

Previous studies by Udjo (1996, 2006, 2008; 2014) that applied the Brass Growth Balance method to South African census data to estimate the completeness of death reporting and deriving mortality rates observed that any violation of the assumptions could be dealt with by selecting the best fitting points of the straight line. This includes the assumption on migration, however, there is a limitation in that where there is significant migration the effect will be there. Udjo and Lalthapersad-Pillay (2014) applied the BGB method at national and provincial levels to estimate completeness of death reporting and computed mortality rates without allowing for net migration despite the volume of subnational migration in South Africa being significant compared to that of Zambia. Dorrington (20/3), on the other hand, notes that the assumption of the population being closed can be relaxed if net migration is small relative to the mortality rates; but cautions that it becomes an issue of concern at sub- national level depending on the magnitude of net migration. In Zambia, Banda et al (2015) applied a combination of Hill's Generalized Growth Balance (GGB) and Synthetic Extinct Generations (SEG) to evaluate completeness of reporting of pregnancyrelated deaths and derive pregnancy-related mortality rates at rural and urban residence level but considered migration to be negligible which is a limitation. The extent of the violation of this assumption on migration in terms of magnitude and its impact on estimates is not easily quantified.

This study, however, extends the application of the BGB to the Zambian census data by allowing for migration unlike the previous studies. To minimise the risk of violating the assumptions, the study fit the straight line to the best possible points at national, rural-urban and provincial levels in order to estimate the level of completeness of death reporting, perform adjustment and subsequently deriving the adult mortality rates at these levels. In fitting the straight line, the study ensured that the chosen age ranges resulted in a level of completeness of death reporting that was not less than 60 per cent as a level below this acceptable threshold could introduce a lot of uncertainty in the plausibility of the mortality estimates (Dorrington 2013: 197). The straight line was fit to the partial birth and death rates from the age range $5+$ to $75+$ years at national and subnational levels. Ages above 75 years were avoided because of age exaggeration. Hill, You and Choi (2009) recommend fitting the straight line to age ranges $5+$ to $65+$ while Dorrington (2013: 197) recommends fitting to age trims $35+$ to $75+$ in order to avoid migration ages if not accounted for as well as age exaggeration at older ages. The choice of age trims ensures that plausible mortality estimates are obtained. The residuals of the fitted points were kept within the acceptable limits of less than I per cent; any points with residuals above this threshold were excluded. In addition, a good fit straight line lessens concerns about the violation of the assumption on migration despite allowing for it.

The study also derived alternative adult mortality rates by applying the Generalized Growth Balance (GGB) method (Hill 1987) using 2000 and 2010 census population age-sex, deaths and migration data. Intercensal deaths between 2000 and 2010 were estimated by taking into account of the growth rates between the two periods and applying the geomean to come up with a death inflation factor. The intercensal migration was estimated as mentioned earlier. The study used the GGB spreadsheet developed by Moultrie et al (20I3). The detailed methodology and assumptions of the GGB method are elaborated elsewhere (Hill 1987; Moultrie, Dorrington, Hill et al. 2013). The estimated GGB 
adult mortality rates were used to validate the $B G B$ mortality estimates.

The study also utilised sibling history survival information from the 2013/2014 Zambia Demographic and Health Survey to directly estimate regional adult mortality rates to validate the $B G B$ mortality rates. The region of residence of the respondent sibling was used as a proxy region of the deceased siblings. The study first reproduced the reported ${ }_{35} q_{15}$ mortality estimates and then extended the method to produce ${ }_{45} q_{15}$ mortality rates (See Table 5 in the appendix). This ensured accuracy in the derived estimates.

To establish the relationship between the estimated regional adult mortality rates and HIV prevalence and literacy rates the study plotted scatter plots, and computed correlation coefficients $(r)$ and coefficients of determination $\left(r^{2}\right)$. The selection of the variables was based on literature that established associations with adult mortality and these variables. The study used information on the variables from the 2013/2014 Zambia Demographic and Health Survey for each region on literacy rates as a proxy for social economic factors and HIV prevalence rates for age group 15-49 to represent health conditions (See Table 5 in the Appendix). The literacy rate is defined as the percentage of women and men who attended secondary school or higher education and men and women who can read a whole sentence or part of a sentence (Central Statistical Office (CSO) [Zambia], Ministry of Health (MOH) [Zambia] and ICF International 2014).

The study could not apply multivariate regression analysis due to limited information collected by the census at individual level for the deceased persons. An attempt to perform multivariate regression analysis would result in the model being incorrectly specified leading to a lot of unexplained variation because a number of variables that have more influence on adult mortality would not have been considered. The computed correlation coefficients and coefficients of determination, though limited in terms of detail of conclusive associations, are but an alternative to show relationships. The scatterplots show the direction, form and strength of any association, however, the correlation coefficient summarises the strength and direction of a linear relationship; (its values lie between $-I$ and $+I$ ) while the coefficient of determination measures the amount of the total variation in one variable which can be explained by the variation in the other variable (Bruce, Pope and Stanistreet 2008).

\section{Ethical considerations}

The 10 per cent sample datasets of the 2000 and 2010 censuses of population and housing were made available by the Integrated Public Use Microdata Series (IPUMS) and Central Statistical Office in Zambia. Permission was sought and granted to use the datasets. The datasets were stripped off personal identifiers before they were released for public use. The 2013/2014 Zambia Demographic and Health Survey dataset was downloaded with permission from the DHS Program website. Since, there was no fieldwork involved to collect additional data for the study; no ethical clearance was applied for.

\section{Results}

Assessment of population and death data

An assessment of the population age data in Figure I shows that the single-year age distribution fluctuates across ages indicating the presence of errors in reporting of age in form of age misreporting, age heaping, terminal age digit preference ( 0 and 5$)$ and age exaggeration at older ages. Grouping single-year population age distribution data into 5-year age distribution acts as the first step of smoothing the age misreporting in the age data; it can be seen in Figure I that the 5-year grouped population age distribution is smoother than the single-year age distribution. This, however, does not clear the age distribution of age misreporting errors completely. The Arriaga (1994) light smoothing method was further applied to smoothen the age data to minimise the errors in age misreporting. 
Figure I: Single-year and five-year distribution of
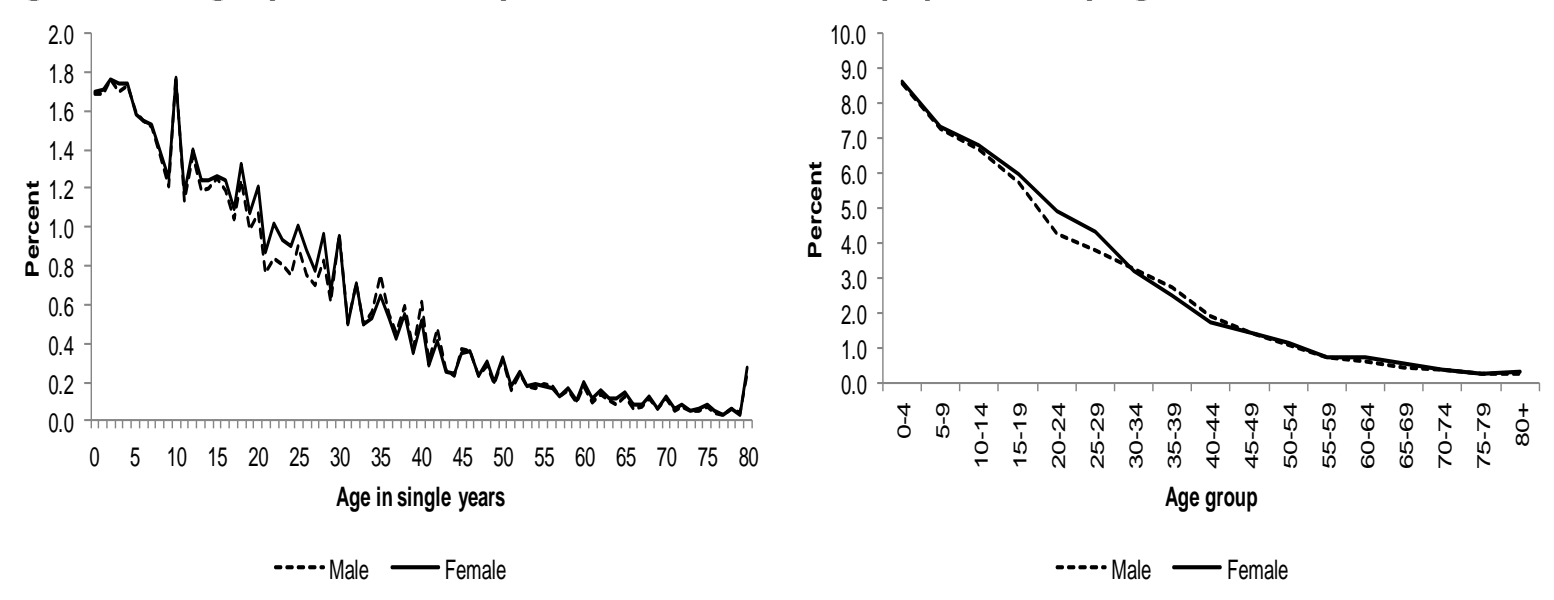

Source: Author computations from 2010 Zambia Census data files.

Reporting of household deaths in Figure 2 shows that for the single-year age distribution, the fluctuations are indicative of errors in the reporting of ages of the deceased persons. When the household deaths are grouped into 5-year age groups, the fluctuations smoothen out. A clear picture of mortality by age group emerges. High under-5 mortality which steeply drops in age group 5-9, and further declines in age group 10-I4, before gradually rising from age group $15-19$ and reaching a peak in age group 25-29 for females, and for males in age group 35-39; thereafter, a gradual decline follows. The percentage of male deaths is higher between age group 30-34 and 45-49 than for females; also known as the "HIV/AIDS hump" in populations with generalised HIV/AIDS epidemic

Figure 2: Single-year and five-year distribution of deaths by age and sex, 2010 Census-Zambia
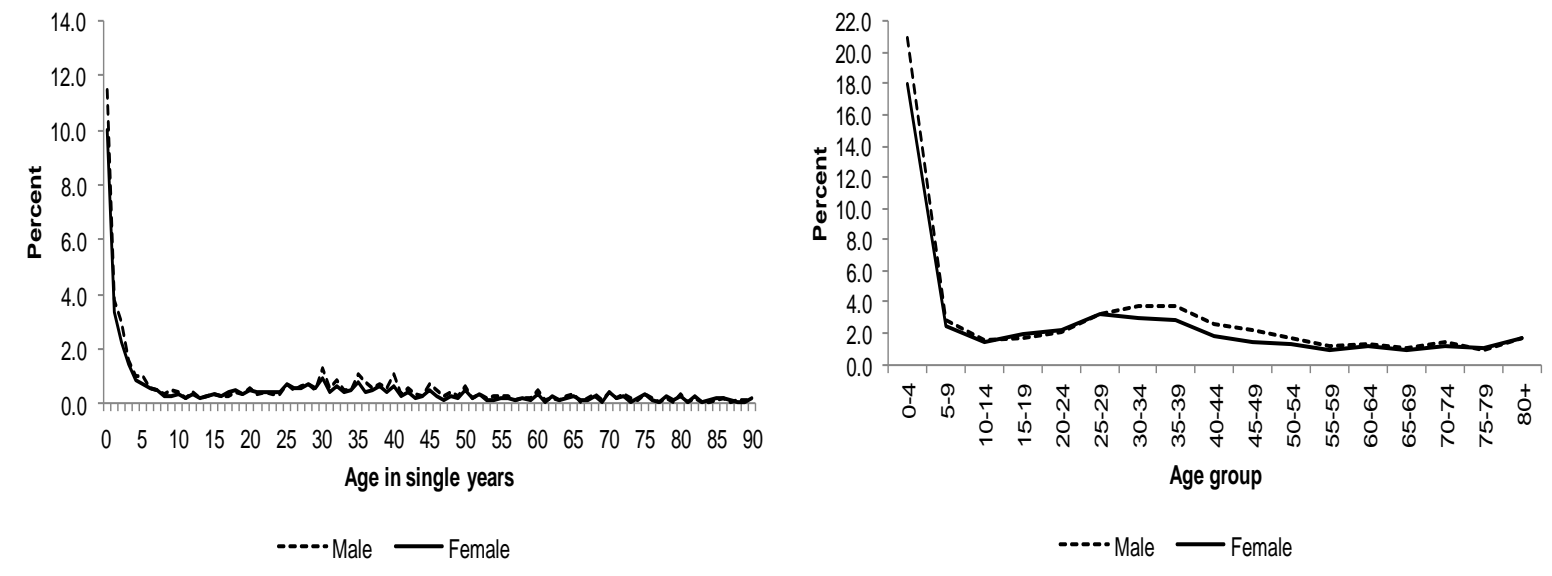

Source: Author computations from 2010 Zambia Census data files.

\section{Completeness of death reporting}

Fitting of the straight line to the partial births and death rates enabled the assessment of the completeness of reporting of deaths at national, rural-urban, and provincial levels by sex. The levels of completeness of reporting of deaths ranged from 68 per cent to 109 per cent for females while that of males ranged from 87 per cent to 135 per cent. It is evident that the reporting of deaths was either under reported or over reported for both males and females. Figure 3 presents the fitting of the straight line to assess the completeness of reporting of deaths for females at national level. The Figure also shows the adjusted mortality rates after applying the Brass Growth Balance method. The completeness of death reporting for females at national level was estimated at 82 per cent (See Table 5 in the appendix). It can be seen from Figure 3 that the fit of partial birth and death rates before adjustment there are curvatures as the points lie on the straight line indicating that there some small numbers of migration that are not accounted for. The Figure also shows that the residuals lie within the acceptable limits of I per cent. It can be observed from Figure 3 that after adjusting 
for completeness of death reporting all the points lie reasonably well. on the straight line and the adjusted mortality rates fit

Figure 3: Fitting of straight line for completeness of reporting of deaths Brass Growth Balance Method, Females-Zambia 2010
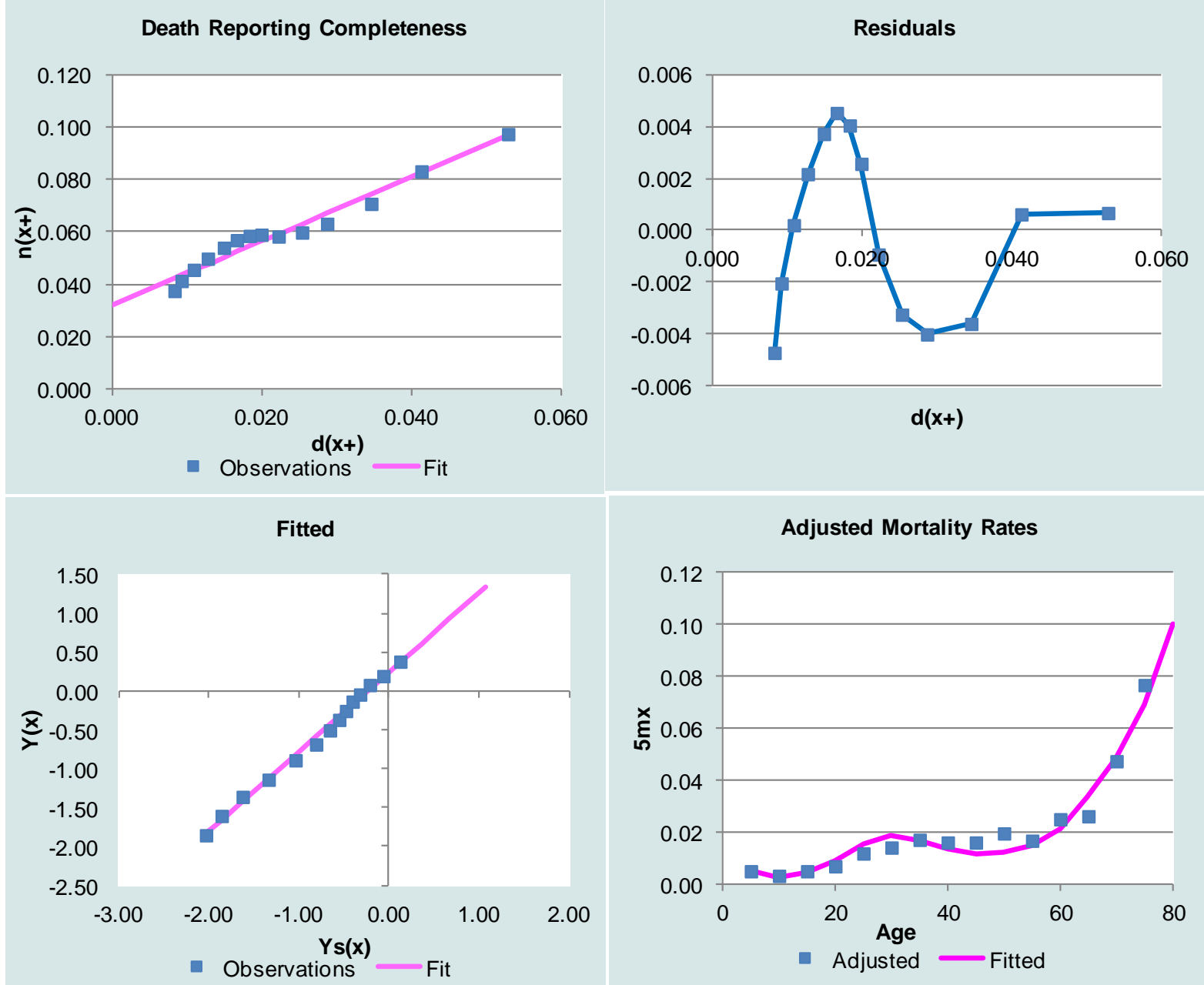

Source:Author computations from 2010 Zambia Census data files.

\section{Distribution of adult deaths}

In 2010, 54.3 per cent of adult deaths in age group 15-59 were male and 45.7 per cent were female at national level. In rural areas, 52.8 per cent and $\mathbf{4 7 . 2}$ per cent of adult deaths were those of males and females, respectively. The mean age at death was 34.6 years for all adult deaths; 35.2 years for males and 33.7 years for females. In rural areas, the mean age at death was 34.5 years for all adult deaths; 35.2 years and 33.6 years for males and females, respectively. In urban areas, the mean age at death was 35.3 years and 33.9 years for males and females, respectively. For all urban adult deaths, the mean age at death was 34.7 years. By the age of 32 years half of the female adults died and for males by the age of 35 , irrespective of rural or urban residence. Table I below shows that adult mortality was higher among men than women in the age group 15-59 years. Mortality was highest in the age group 25-29 for women whereas for men it was in the age group 30 39 years.

Though unexpected when compared to other populations, adult mortality was higher in urban than rural areas. In both rural and urban areas, adult mortality was higher in the age group 25-39. In comparison, more female adult deaths occurred in rural areas than urban areas in total. In addition, the proportion of female adult deaths in the age group 25-29 was higher than for males in both rural and urban areas. Furthermore, the proportion of adult females who died from sickness and disease was also higher than for males in both rural and urban areas. Conversely, the percentage of adult male deaths attributed to accidents and injuries were twice as high as those of females. Similarly, the proportion of adult male deaths due to suicide and violence was higher than for females in both urban and rural areas. 
Table I: Percentage distribution of adult deaths by age, sex, cause of death and rural-urban residence, Zambia 2010

\begin{tabular}{ccccccc}
\hline & \multicolumn{2}{c}{ Rural } & \multicolumn{2}{c}{ Urban } & \multicolumn{2}{c}{ Total } \\
\cline { 2 - 6 } & Male & Female & Male & Female & Male & Female \\
\hline
\end{tabular}

\section{Age group}

\begin{tabular}{lcccccc}
$15-19$ & 9.3 & 11.0 & 5.5 & 9.3 & 7.5 & 10.2 \\
$20-24$ & 9.9 & 12.1 & 9.3 & 12.0 & 9.6 & 12.1 \\
$25-29$ & 13.6 & 16.8 & 15.4 & 17.7 & 14.5 & 17.2 \\
$30-34$ & 15.1 & 14.9 & 18.8 & 17.0 & 16.9 & 15.8 \\
$35-39$ & 16.1 & 14.8 & 17.5 & 15.0 & 16.8 & 14.9 \\
$40-44$ & 12.1 & 10.6 & 11.5 & 9.4 & 11.8 & 10.1 \\
$45-49$ & 10.1 & 7.8 & 10.2 & 7.5 & 10.2 & 7.7 \\
$50-54$ & 7.5 & 7.2 & 7.3 & 7.2 & 7.4 & 7.2 \\
$55-59$ & 6.2 & 4.8 & 4.4 & 4.9 & 5.3 & 4.9 \\
& & & & & & \\
Cause of death & & & & & & \\
Accidents and injuries & 7.3 & 2.9 & 6.4 & 2.4 & 6.8 & 2.7 \\
Suicide and violence & 5.0 & 1.8 & 3.4 & 2.5 & 4.2 & 2.1 \\
Sickness and disease & 72.3 & 78.6 & 80.5 & 86.3 & 76.3 & 82.1 \\
All other causes & 15.4 & 16.7 & 9.8 & 8.8 & 12.7 & 13.1 \\
& & & & & & \\
Total & 100.0 & 100.0 & 100.0 & 100.0 & 100.0 & 100.0 \\
Number (15-59) & 1862 & 1663 & 1770 & 1398 & 3632 & 3061 \\
\hline
\end{tabular}

Source: Author computations from 2010 Zambia Census data files.

\section{Age Specific Mortality Rates}

Figure 4 shows the adult age-specific mortality rates (ASMRs) for both males and females. Generally, ASMRs for both males and females progressively increase with age except in some age groups where there are fluctuations. Variations in ASMRs are evident across provinces. Western province experienced the highest ASMRs for both males and females. Muchinga and North-western provinces had generally lower ASMRs for females. Urban ASMRs are higher than rural ASMRs. For Zambia, ASMRs for both males and females lie in the middle.

Figure 4: Age-specific mortality rates, Zambia 2010
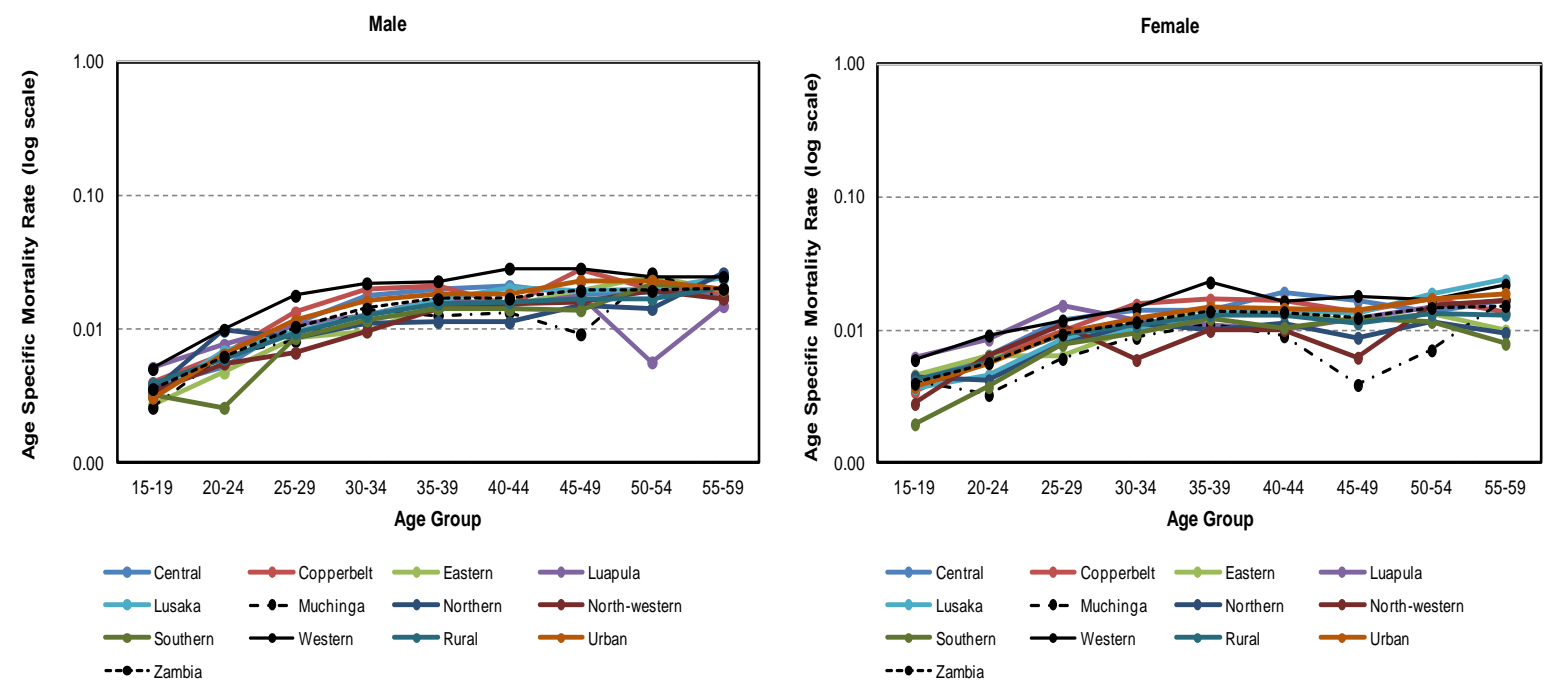

Source:Author computations from 2010 Zambia Census data files. 
Provincial (regional) variations in the distribution of adult deaths

Figure 5 below shows that Copperbelt province had the highest proportion (19.2 per cent) of adult deaths in the age group 15-59 out of the total deaths for all provinces in Zambia. Lusaka province had the second highest proportion of adult deaths. These two provinces are the most developed and urbanised in the country. Muchinga province had the lowest proportion of adult deaths (3.9 per cent), followed by North-Western province (4.2 per cent). Muchinga province is predominantly rural while North-Western is a fast developing province with heavy mining investment to exploit the large copper deposits found in the area.

Figure 5: Percentage distribution of adult deaths by province, Zambia 2010

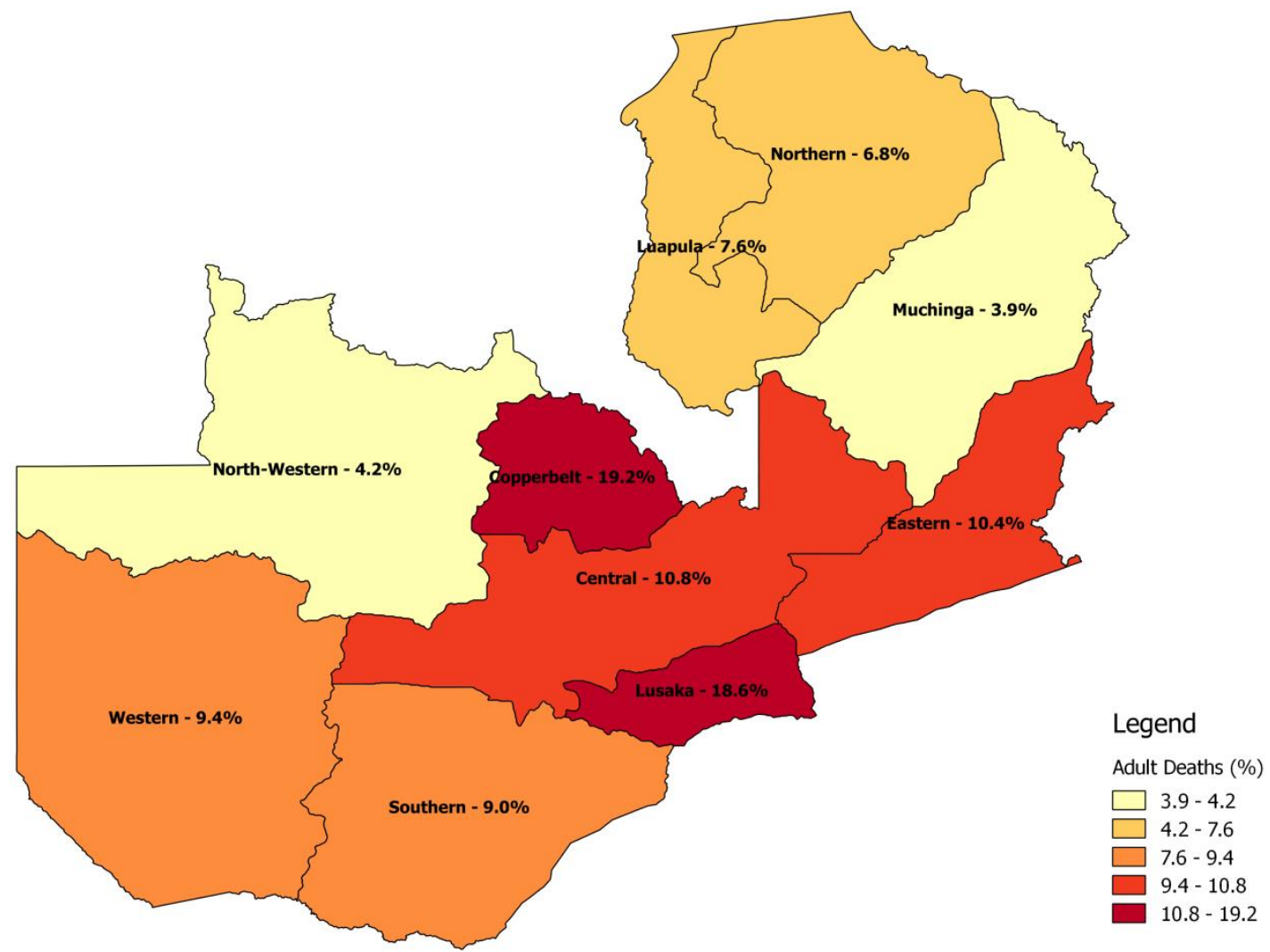

Source: Author generated from 2010 Zambia Census data files using QGIS 
Table 2: Percentage distribution of adult deaths by age, sex, cause of death and province, Zambia 2010

\begin{tabular}{|c|c|c|c|c|c|c|c|c|c|c|c|c|c|c|c|c|c|c|c|c|c|c|}
\hline & \multicolumn{2}{|c|}{ Central } & \multicolumn{2}{|c|}{ Copperbelt } & \multicolumn{2}{|c|}{ Eastern } & \multicolumn{2}{|c|}{ Luapula } & \multicolumn{2}{|c|}{ Lusaka } & \multicolumn{2}{|c|}{ Muchinga } & \multicolumn{2}{|c|}{ Northern } & \multicolumn{2}{|c|}{ North-western } & \multicolumn{2}{|c|}{ Southern } & \multicolumn{2}{|c|}{ Western } & \multicolumn{2}{|c|}{ Total } \\
\hline & Male & Female & Male & Female & Male & Female & Male & Female & Male & Female & Male & Female & Male & Female & Male & Female & Male & Female & Male & Female & Male & Female \\
\hline \multicolumn{23}{|l|}{ Age group } \\
\hline $15-19$ & 7.7 & 10.1 & 6.8 & 8.1 & 6.9 & 12.3 & 11.4 & 13.3 & 5.4 & 9.4 & 6.6 & 15.3 & 8.4 & 13.8 & 9.4 & 9.0 & 9.4 & 6.9 & 7.5 & 10.0 & 7.5 & 10.2 \\
\hline $20-24$ & 7.7 & 11.6 & 8.2 & 11.4 & 8.6 & 14.1 & 11.4 & 14.4 & 10.5 & 10.9 & 11.9 & 9.9 & 16.4 & 10.3 & 10.7 & 15.7 & 5.5 & 10.6 & 10.5 & 13.4 & 9.6 & 12.1 \\
\hline $25-29$ & 13.8 & 17.6 & 15.3 & 15.9 & 13.6 & 12.0 & 14.2 & 23.5 & 14.4 & 17.7 & 13.2 & 15.3 & 13.2 & 17.7 & 11.4 & 23.9 & 15.2 & 18.6 & 16.9 & 14.7 & 14.5 & 17.2 \\
\hline $30-34$ & 18.3 & 16.2 & 19.8 & 18.6 & 12.8 & 14.7 & 15.0 & 12.9 & 17.0 & 16.2 & 18.5 & 16.2 & 14.4 & 16.7 & 14.1 & 9.7 & 17.3 & 17.2 & 16.6 & 14.0 & 16.9 & 15.8 \\
\hline $35-39$ & 18.0 & 12.7 & 17.0 & 15.7 & 17.2 & 16.8 & 17.1 & 10.2 & 18.3 & 15.1 & 14.6 & 17.1 & 12.8 & 13.3 & 16.8 & 12.7 & 17.3 & 17.2 & 14.5 & 16.7 & 16.8 & 14.9 \\
\hline $40-44$ & 14.1 & 12.1 & 8.8 & 10.8 & 11.7 & 11.1 & 12.2 & 6.8 & 14.3 & 9.6 & 11.3 & 9.9 & 9.2 & 10.3 & 12.8 & 9.0 & 11.2 & 10.2 & 13.0 & 9.0 & 11.8 & 10.1 \\
\hline $45-49$ & 8.8 & 8.7 & 12.4 & 7.9 & 11.9 & 8.1 & 11.0 & 7.2 & 9.2 & 7.2 & 6.0 & 3.6 & 10.0 & 6.9 & 10.1 & 4.5 & 9.1 & 9.5 & 9.3 & 8.7 & 10.2 & 7.7 \\
\hline $50-54$ & 6.9 & 6.1 & 6.8 & 7.6 & 11.1 & 7.2 & 2.8 & 6.8 & 6.1 & 7.9 & 12.6 & 4.5 & 6.8 & 6.9 & 8.7 & 9.0 & 9.7 & 6.9 & 6.9 & 7.4 & 7.4 & 7.2 \\
\hline $55-59$ & 4.8 & 4.9 & 4.8 & 4.1 & 6.1 & 3.6 & 4.9 & 4.9 & 4.8 & 5.9 & 5.3 & 8.1 & 8.8 & 3.9 & 6.0 & 6.7 & 5.5 & 2.9 & 4.8 & 6.0 & 5.3 & 4.9 \\
\hline \multicolumn{23}{|l|}{ Cause of death } \\
\hline Accidents and injuries & 5.6 & 4.0 & 5.2 & 2.2 & 4.4 & 2.4 & 9.3 & 1.1 & 6.8 & 3.3 & 7.9 & 1.8 & 9.2 & 4.9 & 8.7 & 2.2 & 10.6 & 2.9 & 5.7 & 1.3 & 6.8 & 2.7 \\
\hline Suicide and violence & 6.1 & 3.2 & 3.0 & 2.7 & 7.5 & 0.6 & 1.6 & 1.5 & 4.1 & 1.8 & 2.0 & 0.0 & 3.2 & 2.5 & 11.4 & 3.7 & 2.4 & 2.6 & 3.6 & 2.0 & 4.2 & 2.1 \\
\hline Sickness and disease & 79.0 & 82.4 & 82.4 & 87.0 & 76.9 & 82.0 & 69.5 & 80.3 & 77.9 & 84.7 & 68.2 & 81.1 & 74.8 & 72.4 & 58.4 & 73.9 & 73.3 & 79.9 & 76.5 & 82.3 & 76.3 & 82.1 \\
\hline All other causes & 9.3 & 10.4 & 9.4 & 8.1 & 11.1 & 15.0 & 19.5 & 17.0 & 11.2 & 10.1 & 21.9 & 17.1 & 12.8 & 20.2 & 21.5 & 20.1 & 13.6 & 14.6 & 14.2 & 14.4 & 12.7 & 13.1 \\
\hline Total & 100.0 & 100.0 & 100.0 & 100.0 & 100.0 & 100.0 & 100.0 & 100.0 & 100.0 & 100.0 & 100.0 & 100.0 & 100.0 & 100.0 & 100.0 & 100.0 & 100.0 & 100.0 & 100.0 & 100.0 & 100.0 & 100.0 \\
\hline Number (15-59) & 377 & 346 & 731 & 555 & 360 & 333 & 246 & 264 & 706 & 542 & 151 & 111 & 250 & 203 & 149 & 134 & 330 & 274 & 332 & 299 & 3632 & 3061 \\
\hline
\end{tabular}

Source: Author computations from 2010 Zambia Census data files 
A comparison across all the provinces as shown in Table 2 above, confirms that as noted earlier adult deaths for both males and females are higher in age group 25-39 relative to the other age groups. The proportion of adult female deaths remained high in age group 25-29, and it was higher in Luapula (23.5 per cent) and North-western (23.9 per cent) provinces.

By cause of death, Luapula (9.3 per cent), Northern (9.2 per cent) and Southern (I0.6 per cent) provinces reported high proportions of adult male deaths due to accidents and injuries. Additionally, the number of adult male deaths was higher than for females across all the 10 provinces. However, Copperbelt and Lusaka provinces had the biggest number of male and female adult deaths. On the other hand, Muchinga and North-western provinces had the smallest number of male and female adult deaths. Table 2 above also shows that the percentage of adult female deaths attributed to sickness and disease was higher than for males across all the provinces. As expected, adult male deaths due to accidents and injuries were higher than for females.

Standardization of provincial variations in adult crude death rates

The study performed a demographic standardization of adult mortality deaths to account for the effect of age by applying the national age-specific mortality rates for the age group 15-59 years which revealed that Muchinga and Southern provinces had the highest adult mortality rates $\mid .21$ times when compared to the national one as shown in Table 3 below. Whereas Western province had the lowest adult mortality in comparative terms controlling for the effect of age to the national mortality rate.

Table 3: Standardization of mortality rates by province, Zambia 2010

\begin{tabular}{lccc}
\hline Province & $\begin{array}{c}\text { Crude Death } \\
\text { Rate }\end{array}$ & $\begin{array}{c}\text { Standardised } \\
\text { Death Rate }\end{array}$ & $\begin{array}{c}\text { Standard Mortality } \\
\text { Rate [CI, 95\%] }\end{array}$ \\
\hline Central & 11.2 & 8.9 & $0.86[0.80-0.93]$ \\
Copperbelt & 12.2 & 8.3 & $0.80[0.74-0.86]$ \\
Eastern & 9.4 & 10.6 & $1.03[0.97-1.09]$ \\
Luapula & 10.8 & 9.4 & $0.92[0.87-0.97]$ \\
Lusaka & 10.2 & 10.0 & $0.97[0.92-1.03]$ \\
Muchinga & 8.0 & 12.5 & $1.21[1.14-1.29]$ \\
Northern & 8.9 & 11.3 & $1.10[1.01-1.18]$ \\
North-Western & 8.7 & 11.4 & $1.11[1.01-1.21]$ \\
Southern & 7.9 & 12.4 & $1.21[1.09-1.34]$ \\
Western & 14.7 & 6.8 & $0.66[0.59-0.75]$ \\
\hline
\end{tabular}

Source: Author computations from 2010 Zambia Census data files. Cl: Confidence Interval

Regional variations in probability of dying between age 15 and 60 years $\left({ }_{45} q_{15}\right)$

A comparison of adult mortality rates across the regions measured by the probability of dying between age 15 and 60 years as shown in Figure 6; confirms that the chances of dying were higher for males than females. It is also evident that males in the Western province had the highest probability of dying at 59.4 per cent. Copperbelt (56 per cent) and Lusaka (54.8 per cent) provinces equally had higher probabilities of adult mortality. The probability of dying was highest for women in Copperbelt province at about 47.9 per cent. Western ( 47.3 per cent) and Luapula (47 per cent) provinces also had high adult mortality. In contrast, North-western province had the lowest probability of adult mortality for both males and females, 36.7 per cent and 34.8 per cent, respectively. Table 4 shows alternative adult mortality estimates derived from the GGB and direct sibling survival methods. Despite differences in the magnitude of the mortality rates both the GGB and direct sibling estimates show that the probability of adult mortality for males is highest in Western province. Copperbelt and Lusaka provinces follow closely. These estimates confirm the level obtained by the BGB method. The probability of adult female mortality is higher in Copperbelt province. North Western province has the lowest probability of adult mortality for both males and females which confirms estimates derived from the BGB.

A plot of HIV prevalence rates obtained from the 2013/14 Zambia Demographic and Health Survey (ZDHS) against the provincial adult mortality rates in Figure 6 shows that the provinces with higher HIV prevalence rates, that is, Copperbelt, Lusaka and Western had male adult mortality rates above 50 per cent. Only North-western province had the lowest adult mortality rates for both males and females. Figure 6 also shows that the probability of dying 
was higher for males $(0.567)$ and females $(0.43 \mathrm{I})$ in urban areas than males (0.398) and females $(0.365)$ in rural areas, and so was the HIV prevalence. Furthermore, the estimated probabilities of dying for Zambia, male (0.488) and female (0.454), are within comparable limits to those of the United Nations Population Division (UNPD) (male 0.458 and female,
0.450 ) for the period $2010-2015$ as indicated in Figure 6. The GGB and direct sibling mortality estimates in Table 4 show a similar pattern of lower adult mortality in rural areas than in urban areas. However, there are differences in the magnitude of the estimates.

Figure 6: Probability of dying between age 15 and 60 years, and Percentage HIV prevalence by province, Zambia 2010, 2013-2014

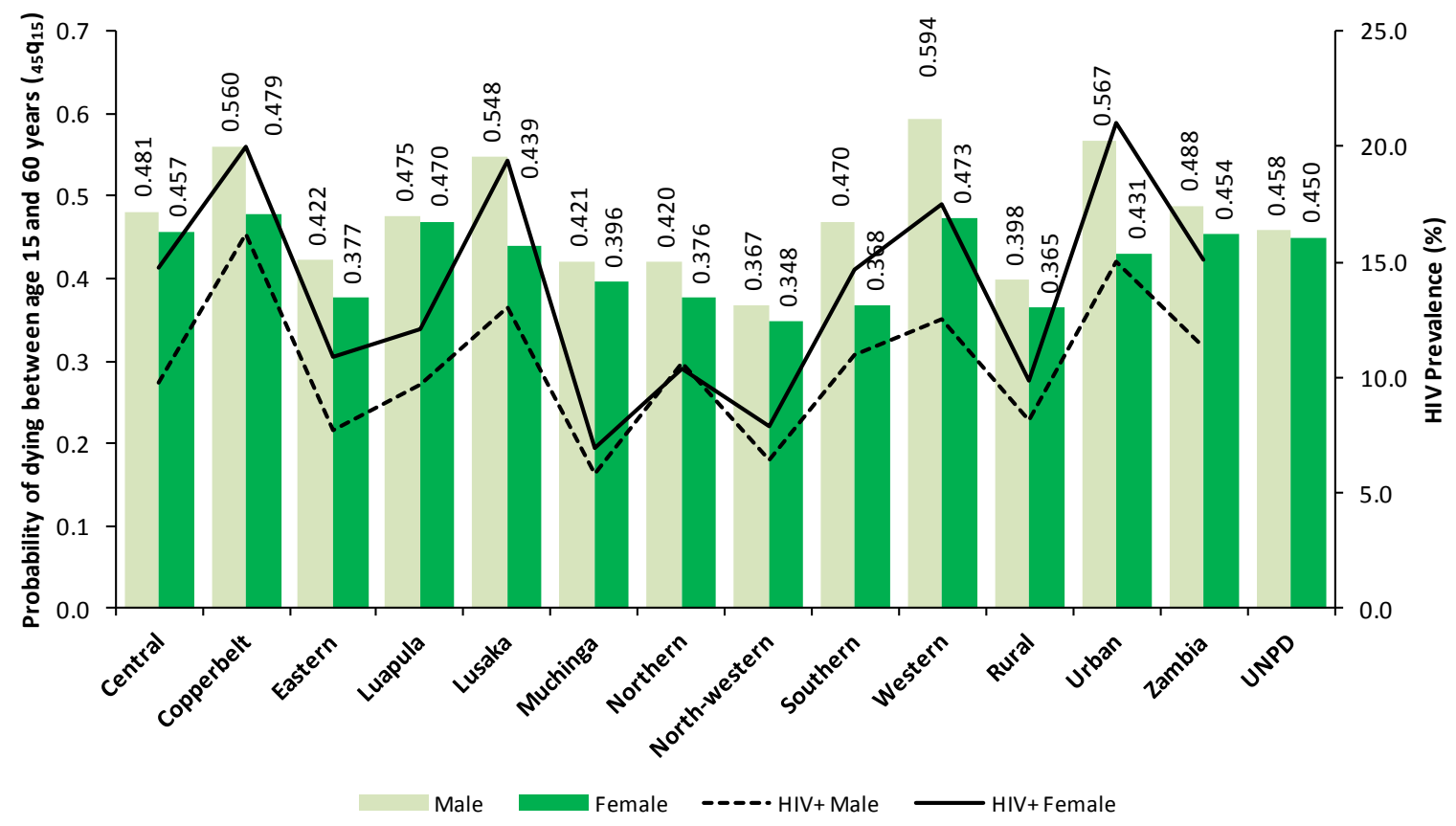

Source:Author computations from 2010 Zambia Census and 2013-14 ZDHS data files

Table 4: Generalized Growth Balance and Direct Sibling estimates of probability of dying between age 15 and 60 years $\left({ }_{45} q_{15}\right)$

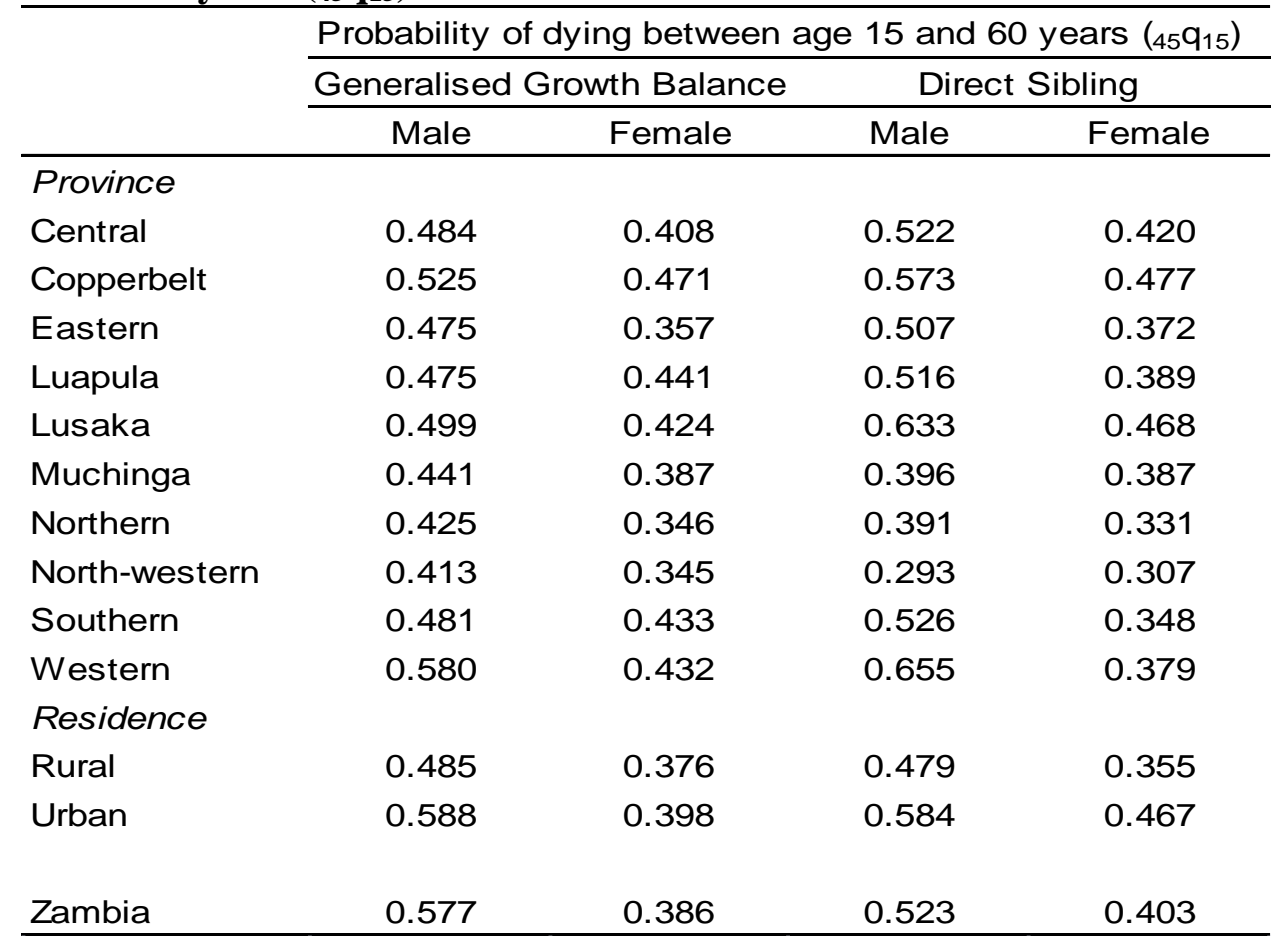

Source: Author computations from 2000 and 2010 Zambia Census data files; 2013/20I4 ZDHS sibling survival data. 
Relationship between regional adult mortality rates ${ }_{45} q_{15}$ ) and social economic status and HIV prevalence Figure 7 below describes the relationship between estimated regional adult mortality rates and HIV prevalence rates. From the figure, adult mortality rates varied for different HIV prevalence rates. A strong positive linear relationship is observed between the adult mortality rates and HIV prevalence for males $(r=0.843)$ with about $71\left(r^{2}=0.7098\right)$ per cent of the total variation in adult mortality rates explained by the variation in HIV prevalence rates.
The remaining 29 per cent of the variation is left unexplained and must be due to other factors which have not been considered in the analysis or which are unknown. For females, a moderately strong positive linear relationship is observed $(r=0.690)$ with about $48\left(r^{2}=0.4761\right)$ per cent of the variation in mortality rates explained by HIV prevalence. The positive correlation coefficient for both males and females show that, on the whole, adult mortality rates increase as HIV prevalence rates increase.

Figure 7: Relationship between Probability of dying between age I5 and 60 years, and Percentage HIV prevalence by province, Zambia 2010, 20I3-2014
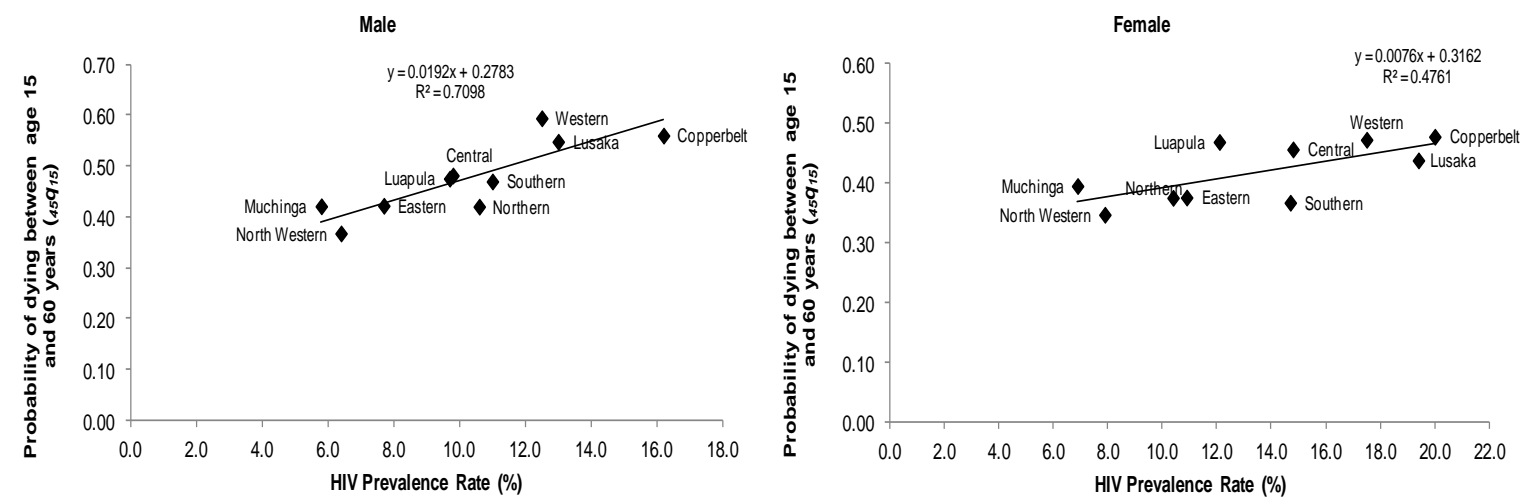

Source: Author computations from 2010 Zambia Census data files

Figure 8 shows that adult mortality rates varied for different literacy rates. For males $(r=0.519)$, a moderate positive linear relationship is observed while for females $(r=0.390)$, a weak positive linear relationship exists between regional adult mortality rates and literacy rates. About 27 per cent $\left(r^{2}=0.2697\right)$ of the variation in adult mortality rates for males and 15 per cent $\left(r^{2}=0.1517\right)$ for females is explained by the variation in literacy rates. Though inconclusive, the positive correlation coefficients for both males and females imply that adult mortality rates increase as literacy rates increase.

Figure 8: Relationship between Probability of dying between age 15 and 60 years, and Literacy Rate by province, Zambia 2010, 2013-2014
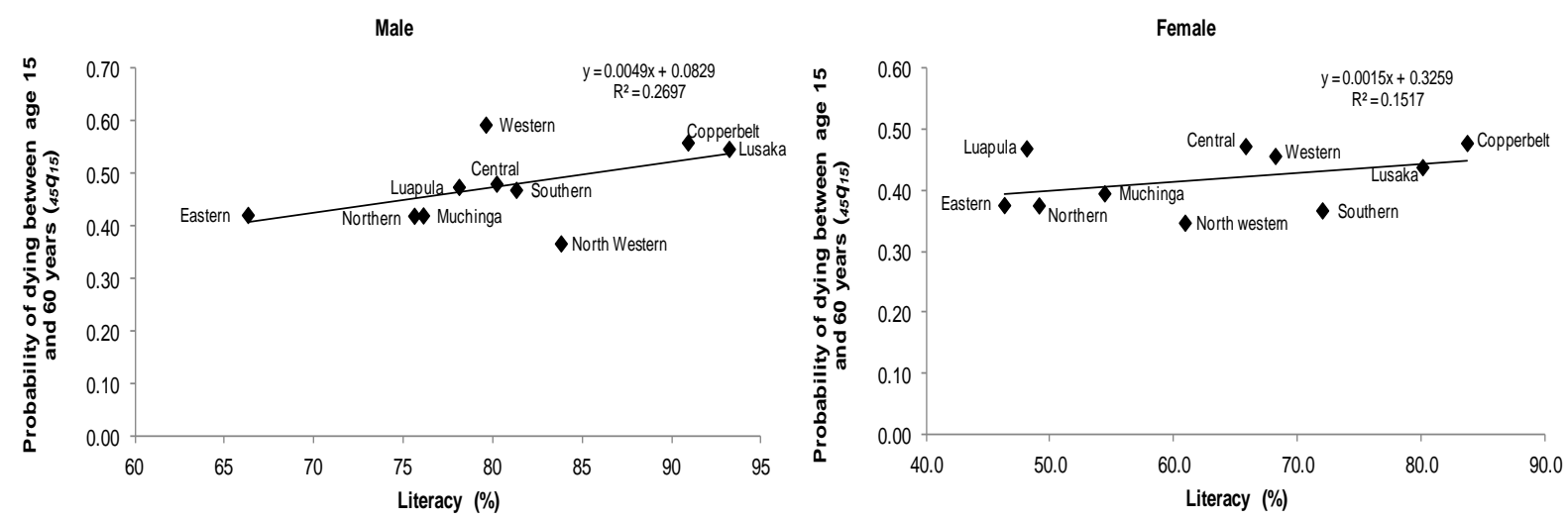

Source: Author computations from 2010 Zambia Census data files 


\section{Discussion}

The study aimed at estimating adult mortality rates at sub-national level and relates them to HIV prevalence and literacy rates. As expected, the study found variations in estimated adult mortality rates. Males experienced higher mortality than females as expected in most populations. By age group, female mortality was higher in age group 25-29 years, whereas for males it was in age group 30-39 years. By the age of 32 half of the females had died. The high proportion of female adult deaths in age group 25-29 observed across all provinces and by ruralurban residence is a cause of concern and requires further investigation. It may also be possible that most of these deaths to could be attributed to maternal causes or HIV/AIDS. The concentration of adult deaths in the age group 25-39 is characteristic of AIDS mortality, "HIV/AIDS hump", when compared to low HIV prevalence populations. This finding is consistent with a study by Banda (2015) that found high maternal deaths in Luapula and Northern provinces. The finding is also in agreement with another study by Banda et al. (2015) who found high female adult mortality in the age group 25-29 when they examined pregnancy-related deaths in Zambia; mortality was higher in urban than rural areas. In another cohort study by Dzekedeke et al. (2008) conducted in selected communities of Zambia also found high young adult female mortality of which 74 per cent was attributed to HIV/AIDS. Furthermore, another multi-year population level study conducted in Lusaka urban district from 2004 to 201 I by Rathod et al. (2016) found high mortality among younger adult females aged between 20 and 40 years. Away from HIV/AIDS, Banda et al (2016) found that social, economic and cultural factors in Zambia limited women's access to modern maternal health services; implying that the status of women and gender inequalities in society influence who receives health care services-especially in poor societies-ultimately impacting on female mortality.

The study found that urban areas experienced higher adult mortality than rural areas. This finding was unexpected as urbanisation is associated with modernisation, socioeconomic groups with higher incomes, better infrastructure, and access to health and social services. The expectation, therefore, was that adult mortality rates would be lower in urban areas than rural areas. Interestingly even life expectancy at birth in 2010 was lower in urban areas ( 50.8 years) than in rural areas ( 51.7 years) in Zambia (Central Statistical Office (CSO) 20I2). Furthermore, the last three demographic and health surveys (200I/2; 2007 and 20I3/I4 ZDHS) conducted in Zambia and tested for HIV/AIDS consistently reported HIV prevalence rates in urban areas that were twice as high as those in rural areas (Central Statistical Office, Central Board of Health and ORC Macro 2003; Central Statistical Office, Ministry of Health, Tropical Diseases Research Centre et al. 2009; Central Statistical Office (CSO) [Zambia], Ministry of Health (MOH) [Zambia] and ICF International 20I4).

In another nation-wide HIV testing study conducted by the Ministry of Health it was found that HIV prevalence was higher among urban adults than rural adults (Chanda-Kapata, Kapata, Klinkenberg et al. 20I6). Given this scenario, the higher HIV prevalence rates in urban areas could have led to the observed higher adult mortality rates than in rural areas. The study finding is consistent with Banda et al (20I5) who also found higher pregnancy-related mortality among females in urban areas than rural areas in Zambia. It also follows that the most urbanised provinces of Zambia, Copperbelt and Lusaka, experienced more adult deaths, higher probability of adult men dying, and high HIV prevalence rates compared to the other provinces. These findings support the study's first hypothesis that adult mortality rates were positively associated with HIV prevalence. On the other hand, they do not support the second hypothesis that adult mortality rates were negatively associated with literacy rates. The study expected that higher literacy rates would be associated with lower adult mortality rates. Though inconclusive, it requires further investigation. Conversely, the 2013/20I4 Zambia Demographic and Health Survey found higher HIV prevalence rates among those with secondary and more than secondary level of education. In fact, for females, HIV prevalence rates increased progressively with level of education (Central Statistical Office (CSO) [Zambia], Ministry of Health (MOH) [Zambia] and ICF International 2014).

An examination of the causes of death among adults revealed that mortality in the age group 25-39 years for both men and women was mainly as a result of sickness and disease. A higher proportion of females than males, however, died from sickness and disease across all provinces and by rural-urban residence. Though the census questionnaire did not specify a category for HIV/AIDS as a cause of death; however, the Institute for Heath Metrics and Evaluation, through the global burden of disease study of 2013 also reported that HIV/AIDS, malaria and lower respiratory infections were the leading causes of death in Zambia (www.healthdata.org) (GBD 2015 Disease and Injury Incidence and Prevalence Collaborators. 2016; GBD 2015 Mortality and Causes of Death Collaborators. 2016; Wang 20I6). Another study by Mudenda et al. (20I I) found that HIV/AIDS and malaria were the leading causes of 
death among adults. Furthermore, Rathod et al. (2016) also found that the top three most common causes of adult deaths in Lusaka urban district were tuberculosis, HIV/AIDS and malaria in that order. It is known that tuberculosis is closely associated with HIV/AIDS (Naidoo, Grobler, Deghaye et al. 2015; Samandari, Agizew, Nyirenda et al. 2015). There are also studies though inconclusive that have linked malaria to HIV/AIDS (Abu-Raddad, Patnaik and Kublin 2006; Mermin, Ekwaru, Liechty et al. 2006; Mandisodza 20l0).

In addition, the pattern of the age gap observed in adult deaths between men and women could possibly be attributed to inter-generational sex whereby females are in sexual relationships with older males and get infected at younger ages; a behavioural pattern observed in populations experiencing high HIV/AIDS prevalence (Dzekedzeke, Siziya and Fylkesnes 2008).

Male deaths attributed to accidents and injuries were twice as high as those of females. Accidents and injury deaths in Zambia have increased and it is projected that deaths from these causes are likely to exceed those attributed to HIV/AIDS (World Health Organization (WHO) 2013; Lusakatimes.com 2014, 2015). Furthermore, deaths attributed to suicide and violence were also higher among males than females. Poverty levels are high in Zambia as noted earlier, about 61 per cent of the population live on less than I dollar a day. The economic performance of the country has been sluggish. This has put a lot of people under economic pressure in terms of their livelihoods. Other studies conducted in South Africa, Japan, Canada and South Korea also had similar findings that deaths due to suicide and violence were high among males as a result of economic pressure, alcohol and drug abuse, and poverty (Trovato and Heyen 2006; Yang, Khang, Chun et al. 2012; Naidoo and Schlebusch 2014; World Health Organization (WHO). 20I4; Matzopoulosa, Prinslooa, Pillay-van Wyka et al. 20I5).

Standardization of mortality rates across the regions revealed that controlling for the effect of age on adult mortality unmasks what is concealed by age which points to other factors being responsible for adult mortality variations that require further investigation. It also showed a link between age and HIV/AIDS as regions that had high adult mortality coupled with high HIV prevalence rates did not continue having high mortality after standardisation.

The probability of dying between age 15 and 60 years varied across the provinces. It is evident that the pattern of adult mortality variation in the regions is closely linked to HIV/AIDS as pointed out earlier. Western province had the highest probability of adult mortality for males and HIV prevalence is high. The province has quiet a large fishing community and some studies have found higher HIV prevalence in these communities. Copperbelt province, is highly urbanised and compact, had the highest probability of dying for females and had high HIV prevalence whereas North-western had both the lowest adult mortality and HIV prevalence for both males and females. North-western province is still predominantly rural but in the process of urbanizing due to increased mining activities in the area. Central province is a transit point of two major international highway trucking routes-one to Congo DRC and the other to Tanzania-as well as the railway line. Consequently, the relatively high HIV prevalence rates could explain the high adult mortality rates among females in the province. Luapula province has fishing communities as noted earlier HIV prevalence could be contributing to high adult mortality rates among females.

The contribution of this study is in deriving adult mortality estimates by region or province, and ruralurban residence which were previously unknown in Zambia to the best of our knowledge. The study has also shown that, though inconclusive, regional adult mortality rates are positively associated with HIV prevalence rates and literacy rates. From these estimates, it could be deduced that despite the ART, TB and malaria programmes implemented in Zambia, adult mortality remains high and a public health challenge even at regional level. The plausibility of the derived provincial adult mortality rates might be debatable but they are indicative of the levels of mortality variations in these geographical regions. For example, our adult mortality estimate for Lusaka province derived from sibling survival information is close to the estimate by Rathod et al. (2016) for Lusaka urban. The regional adult mortality estimates also show that there are regions in Zambia that have even higher mortality rates that are above the national average mortality rates and require special attention. Furthermore, the variations in adult mortality rates are indicative of the differences in government and health systems' capability to adequately address the health needs at sub-national level. Therefore, government health interventions should not be implemented in a homogeneous manner across provinces but be responsive to the respective unique environment of each province; this will enable them to more be appropriate and effective.

In research terms, the derived mortality estimates form a basis for refinement in future estimates at regional level. The derived adult mortality rates at national level are comparable to those of the United Nations Population Division; this gives us confidence that the study estimates are within plausible limits. 
On the other hand, the limitations in data availability to produce more accurate adult mortality estimates as well as understand the determinants of adult mortality at sub-national level in Zambia calls for investment in civil and vital registration systems that should provide the needed information to allow for detailed investigation of the subject. In addition, such a system would enhance the monitoring of progress in achieving the Sustainable Development Goals (SDGs) at both national and sub-national levels.

Regional variations in adult mortality matter for policy-planning and health-decision making in the context of Zambia reaping from the demographic dividend as well as addressing the post-20I5 development agenda with respect to the SDGs particularly goal number three "ensure healthy lives and promote well-being for all ages."

The limitations of the study lie in the use of the Brass Growth Balance method to evaluate and adjust the completeness of death reporting. Despite the effort to fit the straight line to the best points to minimise the impact of violating the assumptions, it is possible that despite accounting for migration it could have affected the mortality estimates at provincial level as some provinces experienced more positive or negative net migration. The change in provincial boundaries affecting two provinces, Eastern and Northern, to create Muchinga province-the 10th province-could have had an effect on migration estimates. However, we are unable to determine the magnitude of the impact on the estimates. Second, despite the effort to minimise data errors in age misreporting and age exaggeration at older ages these may still affect the estimates of the level of completeness of death reporting which also extend to adult mortality rates derived, since they cannot be eliminated completely.

Therefore, the derived regional adult mortality estimates should be interpreted in light of the typical errors that are inherent in the data. Third, due to limited information collected by the census, the study was not able to examine the determinants of regional variations in adult mortality using multivariate regression analysis, nonetheless, though inconclusive, correlations were computed to show the relationship between regional adult mortality rates and HIV prevalence and literacy rates. Despite the limitations, the study findings reinforce to some extent the proximate determinants framework of adult mortality. Distal factors, that is, literacy rates; geographical factors-region of residence and urbanrural residence-indirectly influence adult mortality. Proximate factors, that is, health conditions-HIV prevalence-directly influenced adult mortality as seen by the strong positive correlation. Demographic factors, that is, age and sex are also related to adult mortality as shown by the variations.

\section{Conclusions}

Adult mortality in Zambia is high and varies by demographic characteristics and geographical regions as shown by the study. Adult mortality rates were higher in urban areas and in high HIV prevalence regions: Western, Copperbelt and Lusaka provinces. The number of adult deaths was higher for males than females. Adults mainly died from sickness and disease especially in the age group 25-39 years for both males and females. Of concern is the high proportion of female adults who died in the age group 25-29 years compared to males. The observed pattern of adult mortality is characteristic of high HIV prevalence populations. Accidents and injuries are an emerging leading cause of death among adult males in Zambia. This is in addition to the already emerging disease burden of non-communicable diseases for which there is limited health infrastructure and specialised health personnel to address the increasing cases. Regional adult mortality rates were positively associated with HIV prevalence rates and literacy rates.

Based on the study findings, government health interventions and programmes such as those on ART and TB aimed at reducing adult mortality should be designed with appropriate and specific targeted interventions responsive to the regional variations in adult mortality rates. Future research should investigate further the potential determinants behind the observed regional variations in mortality.

\section{Competing interests}

The authors declare that they have no competing interests.

\section{Author Contributions}

VHC conceptualized the paper, acquired the data, conducted the analysis and drafted the manuscript.

NDW provided valuable insights to the paper, did the editorial work and contributed to the discussion of findings. All authors read and approved the final manuscript.

\section{Acknowledgements}

We would like to acknowledge the two anonymous external reviewers for their valuable and expert comments that helped to improve the scope and quality of the earlier versions of the manuscript. We thank the Central Statistical Office [Zambia] and Integrated Public Use Microdata Series (IPUMS) for providing the 2000 and 2010 census 10 per cent sample datasets. We are grateful to the Demographic and Health Survey Program for the 2013/2014 
Demographic and Health Survey dataset for Zambia. VHC is grateful to the University of Zambia and Centers for Disease Control and Prevention-Zambia for the Research Fellowship (Grant Number: CDCRFA-GHI2-I243) and University of Witwatersrand, Postgraduate Merit Award. We are also grateful to the Demography and Population Studies Programme at the University of the Witwatersrand for the writing retreat at which the paper was initially conceptualised.

This article is an extract from the doctoral thesis by the first author at the University of the Witwatersrand, Demography and Population Studies Programme. An earlier version of this paper was presented as a poster at the 6th Cross-Faculty Graduate Symposium held at University of Witwatersrand, 27th-30th October, 2014. A second version was presented in an oral session of the 10th Population Association of Southern Africa (PASA) Conference held from 8th - 10th July, 2015, University of KwaZulu-Natal, Durban, and a third version was presented as a poster at the 7th African Population Conference (APC) held from 30th November to 4th December, 2015 at St. George Hotel, Pretoria, South Africa.

\section{References}

Abu-Raddad, L.J., P. Patnaik and J.G. Kublin. 2006. "Dual Infection with HIV and Malaria Fuels the Spread of Both Diseases in Sub-Saharan Africa", Science 314(5805): 1603-I606.

Adebowale, S.A. and S.A. Adedini. 2014. "Indirect Estimation of Levels of Adult Mortality in SubSaharan Africa," in Odimegwu, C.O. and J. Kekovole (eds). Continuity and Change in SubSaharan African Demography. New York: Routledge, Taylor \& Francis, pp. 78-96.

Ainsworth, M., K. Beegle and G. Koda. 2005. "The impact of adult mortality and parental deaths on primary schooling in north-western Tanzania", Journal of Development Studies 4I (3):4I 2-439.

Arriaga, E.E., P.D. Johnson and E. Jamison. 1994. Population Analysis with MicroComputers. Presentation of Techniques. Washington D.C.: U.S. Census Bureau.

Banda, P.C. 2015. "Status of Maternal Mortality in Zambia: Use Routine Data", African Population Studies 29(2): I820-I830.

Banda, P.C., C.O. Odimegwu, L.F.C. Ntoimo et al. 2016. "Women at Risk: Gender Inequality and Maternal Health", Women \& Health

Banda, R., K. Fylkesnes and I.F. Sandøy. 20I5. "Ruralurban differentials in pregnancy related mortality in Zambia: estimates using data collected in a census", Population Health Metrics I 3(32)
Bendavid, E., C.B. Holmes, J. Bhattacharya et al. 2012. "HIV Development Assistance and Adult Mortality in Africa", Journal of American Medical Association 307(19):2060-2067.

Bennett, N. G. and S. Horiuchi. 198I. "Estimating the Completeness of Death Registration in a Closed Population", Population Index 47(2):202-22I.

Bennett, N. G. and S. Horiuchi. 1984. "Mortality Estimation from Registered Deaths in Less Developed Countries", Demography 21(2):217233.

Bicego, G. 1997. "Estimating Adult Mortality Rates in the Context of the AIDS Epidemic in sub-Saharan Africa: Analysis of DHS Sibling Histories", Health Transition Review 7(suppl 2):S7-22.

Bradshaw, D. and I. M. Timaeus. 2006. "Levels and Trends in Adult Mortality," in Jamison, D.T., R. G. A. Feachem, M.W. Makgoba, et al. (eds). Disease and Mortality in Sub-Saharan Africa. Washington, D.C., USA: The International Bank for Reconstruction and Development/The World Bank, pp.

Brass, W. 1975. Methods for estimating fertility and mortality from limited and defective data: Based on seminars held 16-24 September, 197I at the Centro Latinoamericano de Demografia (CELADE) San Jose, Costa Rica. . Chapel Hill, North Carolina: University of North Carolina, International Program of Laboratories for Population Statistics.

Brass, W., J.A. Coale, P. Demeny et al. 1968. The Demography of Tropical Africa. Princeton, New Jersey: Princeton University Press.

Bruce, N., D. Pope and D. Stanistreet. 2008. Quantitative Methods for Health Research: A Practical Interactive Guide to Epidemiology and Statistics. West Sussex: John Wiley \& Sons Ltd.

Central Statistical Office, Central Board of Health and ORC Macro. 2003. Zambia Demographic and Health Survey 2001-2002. Calverton, Maryland, USA: Central Statistical Office, Central Board of Health, ORC Macro.

Central Statistical Office, Ministry of Health, Tropical Diseases Research Centre et al. 2009. Zambia Demographic and Health Survey 2007. Calverton, Maryland, USA: Central Statistical Office and Macro International.

Central Statistical Office (CSO). 2012. Population and Housing Census-2010: Analytical Report. Lusaka: Central Statistical Office.

Central Statistical Office (CSO) [Zambia], Ministry of Health (MOH) [Zambia] and ICF International. 2014. Zambia Demographic and Health Survey 20/3-14. Rockville, Maryland, USA: Central Statistical Office, Ministry of Health, and ICF International. 
Central Statistical Office (CSO). 2012. Population and Housing Census-2010: Analytical Report. Lusaka: Central Statistical Office.

Chanda-Kapata, P., N. Kapata, E. Klinkenberg et al. 2016. "The adult prevalence of HIV in Zambia: results from a population based mobile testing survey conducted in 2013-2014", AIDS Research and Therapy I3(4)

Chisumpa, V.H. and R. Dorrington. 20I I. "Estimating adult mortality in Zambia using information on survival of parents from surveys", African Population Studies 25(I ): Supplement: I I 3-I 26.

Dorrington, R. 2013. "The Brass Growth Balance Method," in Moultrie, T., R. Dorrington, A. Hill, et al. (eds). Tools for Demographic Estimation. Paris: International Union for the Scientific Study of Population. demographicestimation.iussp.org, pp. 196-208.

Dorrington, R., I. M. Timaeus, T. Moultrie et al. 2004. "Estimates of provincial fertility and mortality in South Africa, 1985-1996", Southern Africa Journal of Demography 9(2):25-57.

Dzekedzeke, K., S. Siziya and K. Fylkesnes. 2008. "The Impact of HIV Infection on Adult Mortality in some Communities in Zambia: A Cohort Study", Tropical Medicine and International Health 13(2): |52-|6|.

Gakidou, E. and G. King. 2006. "Death By Survey: Estimating Adult Mortality without selection bias from Sibling Survival Data", Demography 43(3):569-585.

GBD 2015 Disease and Injury Incidence and Prevalence Collaborators. 2016. " Global, regional, and national incidence, prevalence, and years lived with disability for 310 diseases and injuries, 1990 2015: a systematic analysis for the Global Burden of Disease Study 20I5." The Lancet 388:15451602.

GBD 2015 Mortality and Causes of Death Collaborators. 2016. "Global, regional, and national life expectancy, all-cause mortality, and cause-specific mortality for 249 causes of death, 1980-2015: a systematic analysis for the Global Burden of Disease Study 2015", The Lancet 388: | 459-| 444.

Hill, K. 2003. "Adult mortality in the developing world: What we know and how we know it," Paper presented at Training Workshop on HIV/AIDS and Adult Mortality in Developing Countries, 8-I3 September,2003. New York. United Nations Department of Economic and Social Affairs Population Division.

Hill, K. 1987. "Estimating Census and Death Registration Completeness", Asian and Pacific Population Forum I(3):8-I3.
Hill, K. and J. Trussell. 1977. "Further Developments in Indirect Mortality Estimation", Population Studies 3 I (2):3 I3-334.

Hill, K., D. You and Y. Choi. 2009. "Death distribution methods for estimating adult mortality: sensitivity analysis with simulated error", Demographic Research 2 I (9):235-254.

Hosegood, V. and I. M. Timaeus. 2004. "Levels and causes of adult mortality in rural South Africa: the impact of AIDS", AIDS I8(4):663-67I.

Hummer, R.A. and E.M. Hernandez. 2013. "The Effect of Educational Attainment on Adult Mortality in The United States", Population Bulletin 68(I)

Hummer, R.A. and J.T. Lariscy. 20II. "Educational attainment and adult mortality," in Rogers, R.G. and E.M. Crimmins (eds). International handbook of adult mortality. Vol. 2. Dordrecht, The Netherlands: Springer, pp. 24I-26I.

Kelly, P., R. Feldman, P. Ndubani et al. 1998. "High adult mortality in Lusaka", Lancet 35I(9106):883883.

Khosravi, Ardeshir., Richard. Taylor, Mohsen. Naghavi et al. 2007. "Differential mortality in Iran", Population Health Metrics 5(7)

Lusakatimes.com. 2014. Road traffic accidents double in last six years. In Lusakatimes, Lusakatimes.com, http://www.lusakatimes.com/2014/09/04/roadtraffic-accidents-double-last-six-years/.

Lusakatimes.com. 2015. Over 50 people injured in Chibombo in a bus accident. In Lusakatimes, http://www.lusakatimes.com/20I5/04/I4/over-50people-injured-in-chibombo-in-a-bus-accident/.

Mandisodza, O.T. 20I0. "Malaria and HIV", New Zealand Journal of Medical Laboratory Science 64(I)

Masquelier, B. . 20I3. "Adult mortality from sibling survival data: a reappraisal of selection biases", Demography 50(I ):207-228.

Masquelier, B., G. Reniers and G. Pison. $20 \mid 4$. "Divergences in trends in child and adult mortality in sub-Saharan Africa: survey evidence on the survival of children and siblings ", Population Studies 68(2): 16I-I77.

Matzopoulosa, R., M. Prinslooa, V. Pillay-van Wyka et al. 20I5. "Injury-related mortality in South Africa: a retrospective descriptive study of postmortem investigations", Bulletin World Health Organization 93(5)

Mermin, J., J.P. Ekwaru, C.A. Liechty et al. 2006. "Eff ect of co-trimoxazole prophylaxis, antiretroviral therapy, and insecticide-treated bednets on the frequency of malaria in HIV-I-infected adults in Uganda: a prospective cohort study", Lancet 367:|256-|26|. 
Mikkelsen, L. , D.E. Phillips, C. AbouZahr et al. 2015. "A global assessment of civil registration and vital statistics systems: monitoring data quality and progress", Lancet 386: I395-| 406.

Misganaw, A., D.H. Mariam and T. Araya. 2013." Association of socioeconomic and behavioural factors with Adult mortality: analysis of data from verbal autopsy in Addis Ababa, Ethiopia", BMC Public Health I 3:634.

Moultrie, T., R. Dorrington, A. Hill et al. (eds). 2013. Tools for Demographic Estimation. Paris: International Union for the Scientific Study of Population. demographicestimation.iussp.org,

Mudenda, S.S. , S. Kamocha, R. Mswia et al. $201 \mathrm{I}$. "Feasibility of using a World Health Organizationstandard methodology for Sample Vital Registration with Verbal Autopsy (SAWY) to report leading causes of death in Zambia: results of a pilot in four provinces, 2010", Population Health Metrics 9(40)

Muhwava, W., K. Herbst and M-L. Newell. 2013. "The Impact of HIV-related Mortality on Life Expectancy: Evidence from the Africa Centre Demographic Surveillance Area", Southern African Journal of Demography I2(3):5-28.

Murray, C. J., K.F. Ortblad, C. Guinovart et al. 2014. "Global, regional, and national incidence and mortality for HIV, tuberculosis, and malaria during 1990-2013: a systematic analysis for the Global Burden of Disease Study 2013", The Lancet 384(9947): I 005-1070.

Naidoo, K. , A.C. Grobler, N. Deghaye et al. 2015. "Cost-Effectiveness of Initiating Antiretroviral Therapy at Different Points in TB Treatment in HIV-TB Coinfected Ambulatory Patients in South Africa", JAIDS Journal of Acquired Immune Deficiency Syndromes 69(5):576-584.

Naidoo, S.S. and L. Schlebusch. 2014. Sociodemographic characteristics of persons committing suicide in Durban, South Africa: 20062007", Afr J Prm Health Care Fam Med. 6(I): I-7.

Obermeyer, Z., J.K. Rajaratnam, C.H. Park et al. 2009. "Measuring Adult Mortality Using Sibling Survival: A New Analytical Method and New Results for 44 Countries, 1974-2006," Paper presented at 26th IUSSP International Population Conference, Marrakech 27 September - 2 October, 2009. Marrakech, Morocco.

Rathod, S.D., I.M. Timæus, R. Banda et al. 2016. "Premature adult mortality in urban Zambia: a repeated population-based cross-sectional study", BMJ Open 6:e0 I080I.

Reniers, G., B. Masquelier and P. Gerland. $20 \mathrm{II}$. "Adult Mortality in Africa," in Rogers, R. G. and E.M. Crimmins (eds). International Handbook of Adult Mortality. New York: Springer, pp. I5I-I 70.
Rogers, R. G., B.G. Everett, J.M. Saint Onge et al. 2010. "Social, behavioral, and biological factors, and sex differences in mortality", Demography 47(3 ):555-578.

Rogers, R.G., R.A. Hummer and B.G. Everett. 2013. "Educational differentials in US adult mortality: An examination of mediating factors", Social Science Research 42:465-48I.

Rogers, R.G., R.A. Hummer and P.M. Krueger. 2005. "Adult Mortality," in Poston, D.L. and M. Micklin (eds). Handbook of Population. New York: Kluwer Academic/Plenum Publishers, pp. 283310.

Rossier, C., A.B. Soura, G. Duthe et al. 20I4. "Noncommunicable Disease Mortality and Risk Factors in Formal and Informal Neighbourhoods, Ouagadougou, Burkina Faso: Evidence from a Health and Demograhic Surveillance System ", PLOS ONE 9(I2):el I 3780.

Saikia, Nandita., Domantas. Jasilionis, Faujdar. Ram et al. 2011. "Trends and geographic differentials in mortality under age 60 in India", Population Studies: A Journal of Demography 65(I):73-89.

Samandari, T., T. Agizew, S. Nyirenda et al. 2015. "Tuberculosis incidence after 36 months' isoniazid prophylaxis in HIV-infected adults in Botswana: a posttrial observational analysis", AIDS 29(3):35I359.

Timaeus, I. M. and M. Jasseh. 2004. "Adult mortality in sub-Saharan Africa: Evidence from Demographic and Health Surveys", Demography 4I (4):757-772.

Trovato, F. and N.B. Heyen. 2006. "A varied pattern of change of sex differential in the G7 countries", Journal of Biosocial Science 38:39I-40I .

Udjo, E.O. 1996. "An evaluation of the reported agesex distribution of Botswana in the 1991 Census", Southern Africa Journal of Demography 6(I): I-8.

Udjo, E.O. 2006. "Estimation of Mortality from Vital Registration in South Africa", Current HIV Research 4:469-474.

Udjo, E.O. 2008. "A Re-Look at Recent Statistics on Mortality in the Context of HIV/AIDS with Particular Reference to South Africa", Current HIV Research 6:|43-|5|.

Udjo, E.O. . 2014. "Estimating demographic parameters from the 20II South Africa population census", African Population Studies 28(I: Suppl on Population Issues in South Africa):564 - 578.

Udjo, E.O. and P. Lalthapersad-Pillay. 2014. "Estimating maternal mortality and causes in South Africa: National and provincial levels", Midwifery 30:5|2-5|8.

United Nations. 2002. Methods for Estimating Adult Mortality. New York: Department of Economic 
and Social Affairs. Population Division ESA/P/WP.I 75.

Nations, Department of Economic and Social Affairs, Population Division.

United Nations. 20 I3b. World Population Prospects: The 20/2 Revision. New York: United Nations Department of Economic and Social Affairs.

United Nations. 20I4. Human Development Report 2014: Sustaining Human Progress: Reducing Vulnerabilities and Building Resilience. New York: United Nations Development Programme.

Waite, L. J. 1995. "Does marriage matter? " Demography 32(4):483-507.

Wang, Haidong et al. 2016. " Estimates of global, regional, and national incidence, prevalence, and mortality of HIV, 1980-20I5: the Global Burden of Disease Study 20 15", The Lancet HIV 3(8):e36I - e387.

Weldearegawi, B., M. Spigt and Y. Berhane. 2014. "Mortality level and predictors in a Rural Ethiopian
United Nations. 2013a. World Mortality Report 2013. ST/ESA/SER.A/347. New York: United Population: community based longitudinal study", PLOS ONE 9 (3):e93099.

World Health Organization (WHO). 2009. World Health Statistics 2009. Mortality and burden of disease: Table I. Geneva: World Health Organization.

World Health Organization (WHO). 20I3. Global status report on road safety. Geneva: World Health Organization. www.who.int/violence injury prevention/road sa fety_status Accessed: I I th April, 2015.

World Health Organization (WHO). 2014. The World Health Statistics 2014. www.who.int/gho/publications/world health stati stics/en/ . Accessed I 2 November, 2014

Yang, S., Y-H. Khang, H. Chun et al. 2012. "The changing gender differences in life expectancy in Korea 1970-2005", Social Science \& Medicine 75: $1280-1287$.

\section{Appendix}

Table 5: Brass Growth Balance, Generalized Growth Balance, Direct Sibling estimate of probability of dying between age 15 and 60 years (45q15), Completeness of reporting, HIV prevalence rates and Literacy rates

\begin{tabular}{|c|c|c|c|c|c|c|c|c|c|c|c|c|c|c|}
\hline & \multicolumn{6}{|c|}{ Probability of dying between age 15 and 60 years $\left({ }_{45} 9_{15}\right)^{*}$} & \multicolumn{4}{|c|}{ Percent completeness of death reporting* } & \multirow{2}{*}{\multicolumn{2}{|c|}{$\begin{array}{c}\text { HIV Prevalence (age } \\
\text { group 15-49) }\end{array}$}} & \multirow{2}{*}{\multicolumn{2}{|c|}{ Literacy rate ${ }^{* *}$}} \\
\hline & \multicolumn{2}{|c|}{ Brass Growth Balance } & \multicolumn{2}{|c|}{ Generalised Growth Balance } & \multicolumn{2}{|c|}{ Direct Sibling } & \multicolumn{2}{|c|}{ Brass Growth Balance } & \multicolumn{2}{|c|}{$\begin{array}{c}\text { Generalised Growth } \\
\text { Balance }\end{array}$} & & & & \\
\hline & Male & Female & Male & Female & Male & Female & Male & Female & Male & Female & Male & Female & Male & Female \\
\hline \multicolumn{15}{|l|}{ Province } \\
\hline Central & 0.481 & 0.457 & 0.484 & 0.408 & 0.522 & 0.420 & 99.0 & 75.0 & 85.0 & 97.0 & 9.8 & 14.8 & 80.2 & 68.2 \\
\hline Copperbelt & 0.560 & 0.479 & 0.525 & 0.471 & 0.573 & 0.477 & 91.0 & 91.0 & 99.0 & 95.0 & 16.2 & 20.0 & 90.9 & 83.7 \\
\hline Eastern & 0.422 & 0.377 & 0.475 & 0.357 & 0.507 & 0.372 & 109.0 & 103.0 & 67.0 & 82.0 & 7.7 & 10.9 & 66.3 & 46.3 \\
\hline Luapula & 0.475 & 0.470 & 0.475 & 0.441 & 0.516 & 0.389 & 89.0 & 71.0 & 75.0 & 85.0 & 9.7 & 12.1 & 78.1 & 48.1 \\
\hline Lusaka & 0.548 & 0.439 & 0.499 & 0.424 & 0.633 & 0.468 & 87.0 & 89.0 & 82.0 & 91.0 & 13.0 & 19.4 & 93.2 & 80.1 \\
\hline Muchinga & 0.421 & 0.396 & 0.441 & 0.387 & 0.396 & 0.387 & 100.0 & 68.0 & 99.0 & 68.0 & 5.8 & 6.9 & 76.1 & 54.4 \\
\hline Northern & 0.420 & 0.376 & 0.425 & 0.346 & 0.391 & 0.331 & 106.0 & 85.0 & 94.0 & 91.0 & 10.6 & 10.4 & 75.6 & 49.1 \\
\hline North-western & 0.367 & 0.348 & 0.413 & 0.345 & 0.293 & 0.307 & 135.0 & 109.0 & 77.0 & 93.0 & 6.4 & 7.9 & 83.8 & 60.9 \\
\hline Southern & 0.470 & 0.368 & 0.481 & 0.433 & 0.526 & 0.348 & 101.0 & 96.0 & 75.0 & 64.0 & 11.0 & 14.7 & 81.3 & 72.0 \\
\hline Western & 0.594 & 0.473 & 0.580 & 0.432 & 0.655 & 0.379 & 104.0 & 86.0 & 89.0 & 100.0 & 12.5 & 17.5 & 79.6 & 65.8 \\
\hline \multicolumn{15}{|l|}{ Residence } \\
\hline Rural & 0.398 & 0.365 & 0.485 & 0.376 & 0.479 & 0.355 & 116.0 & 96.0 & 110.0 & 85.0 & 8.1 & 9.9 & 73.4 & 54.3 \\
\hline Urban & 0.567 & 0.431 & 0.588 & 0.398 & 0.584 & 0.467 & 87.0 & 98.0 & 90.0 & 109.0 & 15.0 & 21.0 & 93.2 & 82.8 \\
\hline Zambia & 0.488 & 0.454 & 0.577 & 0.386 & 0.523 & 0.403 & 99.0 & 82.0 & 70.0 & 96.0 & 11.3 & 15.1 & 82.7 & 67.5 \\
\hline UNPD & 0.458 & 0.450 & & & & & & & & & & & & \\
\hline
\end{tabular}

Source: *Author computations from 2000 and 2010 Zambia Census data files

**2013/2014 Zambia Demographic and Health Survey Report 